\title{
Retrieval of temperature profiles using radio acoustic sounding system (RASS) with the equatorial atmosphere radar (EAR) in West Sumatra, Indonesia
}

\author{
Ina Juaeni ${ }^{1}$, Hiraku Tabata ${ }^{2}$, Noersomadi ${ }^{2}$ (D) Halimurrahman ${ }^{1}$, Hiroyuki Hashiguchi ${ }^{2}$ and Toshitaka Tsuda ${ }^{2 *}$ (])
}

\begin{abstract}
The radio acoustic sounding system (RASS) with the equatorial atmosphere radar (EAR) at Koto Tabang, Indonesia was adapted to test the effects of the acoustic source location and acoustic frequency range on the continuous measurement of height profiles of temperature in the tropical troposphere. We installed the acoustic transmitting system by using six high-power horn speakers and four subwoofers. We developed a three-dimensional ray-tracing method of acoustic waves to predict the shape of acoustic wavefronts, accounting for the effects of the background winds on acoustic wave propagation. Then, we selected the appropriate antenna beam directions for EAR that satisfy the Bragg condition between the radar and acoustic wave propagation vectors. We carried out eight campaign observations in 2016, testing the performance of EAR-RASS. We found that the location and acoustic frequency range affected the RASS echoes. We also tested the compensation method of the background wind velocity with EAR to obtain the true sound speed. We intensively analyzed the RASS results from August 29 to September 3, 2016, when radiosondes were launched 12 times from the EAR site. We successfully retrieved the temperature profiles from RASS from 2 to $6-14 \mathrm{~km}$ with time and height resolutions of about $10 \mathrm{~min}$ and $150 \mathrm{~m}$, respectively. Some temperature profiles were obtained up to about the tropopause at $17 \mathrm{~km}$, although the observation period was short. During the RASS campaign, we detected a few interesting events regarding temperature variations as well as large perturbations in the three components of wind velocity.
\end{abstract}

Keywords: Virtual temperature profile, EAR, RASS, Three-dimensional ray tracing, Tropical troposphere, Cloud convection

\section{Introduction}

The behavior of atmospheric disturbances in the tropics was studied by using various observation techniques, such as radiosonde, weather radar, wind profiling radar (WPR), lidars, and satellite images. Mesoscale numerical weather prediction (NWP) models were also adopted to investigate dynamical characteristics during the events of intense cumulonimbus convection, land-sea circulation, and diurnal variations of convective activities (e.g.,

\footnotetext{
*Correspondence: tsuda@rish.kyoto-u.ac.jp

${ }^{2}$ Research Institute for Sustainable Humanosphere (RISH), Kyoto

University, Kyoto, Japan

Full list of author information is available at the end of the article
}

Emanuel 1987; Frank and Cohen 1987; Welsh et al. 1999; Zhang and Fritsch 1988).

Because local and mesoscale effects are more dominant than synoptic influences in the tropics, continuous observations are required. Therefore, ground-based remote sensing techniques are useful for studying tropical convection. Given these conditions, equatorial atmosphere radar (EAR) was constructed in 2001 in Koto Tabang, West Sumatra under intensive collaboration between Japan and Indonesia (Fukao et al. 2003). EAR is equipped with an active phased array antenna and can measure three components of wind velocity. 
In addition to winds, the observation of the atmospheric temperature is vital for clarification of meteorological phenomena. To profile temperature, a balloon-borne radiosonde is commonly employed at an operational weather station. Because the radiosonde is normally released at intervals of 6 to $24 \mathrm{~h}$, the temporal resolution of the soundings is insufficient for the studies of the detailed structure of mesoscale meteorological phenomena. Ground-based remote sensing methods, using radio and optical techniques such as microwave radiometer (e.g., Westwater 1970), Rayleigh and Raman lidars (e.g., Behrendt 2005), and the radio acoustic sounding system (RASS) (e.g., Marshall et al. 1972; Matuura et al. 1986), are developed for continuous monitoring of atmospheric temperature profiles. Among these techniques, we focused on RASS in this study, which is a combination of a high-power sound transmitter and WPR for observations of time and height variations in temperature in the tropical troposphere.

RASS has been applied to WPRs operating at about 50, 400 , and $1.3 \mathrm{GHz}$, corresponding to the acoustic frequency of about $100 \mathrm{~Hz}, 1$, and $3 \mathrm{kHz}$, respectively, considering the Bragg condition between the radar and sound wavelengths (e.g., Masuda et al. 1990; May et al. 1988). Sounds with frequencies higher than a few $\mathrm{kHz}$ immediately decay in the atmosphere because of the effects of turbulence, and therefore, they do not reach great heights (e.g., Clifford and Wang 1977; Peters 2000). Hence, the height coverage was restricted to, at most, several kilometers. However, RASS with a 50-MHz WPR, such as the MU radar in Japan (Matuura et al. 1986; Tsuda et al. 1989, 1994; Adachi et al. 1993) and the Gadanki MST radar in India (Sarma et al. 2008, 2010), used the sound at about $100 \mathrm{~Hz}$, which made it possible to measure atmospheric temperatures up to about $23 \mathrm{~km}$, exceeding the tropopause. Furthermore, the height coverage of RASS was significantly determined by the effects of the background wind velocity on the propagation of acoustic waves (Masuda 1988).

RASS was applied to EAR operating at $47 \mathrm{MHz}$, aiming to measure the temperature in the troposphere over the equatorial region (e.g., Alexander et al. 2006; Furumoto et al. 2006). The intensive campaign called Coupling Processes in the Equatorial Atmosphere (CPEA) was conducted in 2001-2007, by coordinating many observation instruments gathered around the EAR observatory (Fukao 2006). Key results of the CPEA campaigns were summarized in special issues of J. Meteorol. Soc. Japan (2006). The behavior of the tropical convection was reported by Alexander et al. (2006), using EARRASS results. For the RASS experiments, we used fixed antenna beams at five directions, a vertical and four oblique beams at $10^{\circ}$ zenith angle, which are used for the standard wind velocity and turbulence parameter measurements. RASS echoes were not stably obtained because the RASS echoing region did not always exist in these beam directions, being considerably affected by the background winds.

This study is concerned with improvements in the EAR-RASS, by incorporating the ray-tracing method of acoustic waves and investigation of the sound sources. We carried out eight campaign observations with EAR in 2016, testing the performance of RASS. We show a preliminary analysis of the specific disturbance events observed during the EAR-RASS campaign from August 29 to September 3, 2016.

\section{Basic principles of RASS \\ Determination of temperature from sound speed}

For the RASS experiment, we first emit a large sound upward into the sky. Then, the density fluctuations due to the sound waves produce sinusoidal refractive index perturbations that can effectively return the radio scattering (RASS echo). The speed of sound, $C_{\mathrm{s}}$, is determined with WPR from the Doppler frequency shift of the RASS echo. The atmospheric virtual temperature, $T_{\mathrm{v}}$, can be determined using the relationship that the speed of sound is proportional to the square of the atmospheric temperature (see "Appendix").

It is noteworthy that $C_{\mathrm{s}}$ is the sound speed in the air parcel in which the sound waves are propagating. Meanwhile, the ground-based WPR detects the apparent sound speed, $C_{\mathrm{a}}$, which is a summation of $C_{\mathrm{s}}$ and the motion of the air parcel itself. Hence, we need to compensate for the background wind velocity in the direction of the sound wave propagation, $V_{\mathrm{r}}$, before we calculate $T_{\mathrm{v}}$ from $C_{\mathrm{s}}$ (hereafter, we use $T$ as the virtual temperature observed with RASS).

In our study, we combined two sets of radar observation modes-one for the sound speed measurement with the RASS echo and the other for the conventional five-beam wind velocity measurements, pointing the vertical and four oblique beams at $10^{\circ}$ zenith angle into north, east, south, and west azimuth directions. We composed $V_{\mathrm{r}}$ by a vector combination of the vertical and the four radial wind velocities. This manipulation of $V_{\mathrm{r}}$ may induce additional measurement error because of the interpolation of height coordinates and the possible spatial variations in the wind field within the antenna beam steering range.

We additionally employed a third mode to directly measure $V_{\mathrm{r}}$ by steering the antenna beam into the direction of the RASS echoes. Then, we do not need any vector combination or coordinate interpolation for $V_{\mathrm{r}}$. In a later section, we will discuss the improvement in the measurement accuracy of EAR-RASS, comparing the two methods in compensating for the radial winds. 


\section{Bragg condition for RASS echoes}

The Bragg condition is essential in detecting the atmospheric turbulence echo with WPR, requiring that half of the radar wavelength must lie within the turbulence spectrum. This Bragg condition is also applied to RASS, interpreted as the relationship between the wavenumber vectors of radar radio waves, $\vec{k}_{\mathrm{r}}$ and the acoustic waves, $\vec{k}_{\mathrm{a}}$,

$$
\begin{aligned}
& \vec{k}_{\mathrm{a}}=2 \vec{k}_{\mathrm{r}}, \\
& \left|\vec{k}_{\mathrm{a}}\right|=2\left|\vec{k}_{\mathrm{r}}\right|, \\
& \vec{k}_{\mathrm{a}} / / \vec{k}_{\mathrm{r}} .
\end{aligned}
$$

That is, the magnitude ratio of these vectors should be 2:1 (Eq. 2), and these vectors should be parallel (Eq. 3). The former condition requires that the sound wavelength should be half of the radar wavelength, which is called the resonance condition. The latter condition refers to the fact that the radar antenna beam should be steered into the direction perpendicular to the sound wave surface, which is called the orthogonality condition.

\section{3-D ray tracing of sound waves}

To satisfy the orthogonal condition of the Bragg condition, it is important to investigate the propagation characteristics of the sound waves. Then, the antenna beam of WPR should be steered into the appropriate directions that intersect the sound wavefront perpendicularly. The MU radar and EAR have an advantage in the capability to point the antenna beam into any direction by employing the active phased array. Masuda (1988) developed a two-dimensional ray-tracing algorithm for RASS experiments with the MU radar, leading to the expansion of the RASS height coverage. The method was improved to treat a three-dimensional (3-D) case for RASS with Gadanki MST radar (Sarma et al. 2008). However, for the Gadanki MST radar, the antenna beam was steered into only two orthogonal azimuth directions, aligned in the north-south and east-west directions. In this study, we developed a 3-D ray-tracing method, aiming its application of RASS to EAR, having full antenna steerability.

When the sound wave is emitted into the sky, the wave surfaces propagate as approximately concentric spheres. However, the temperature decreases along with height; therefore, the sound speed decreases with increasing height. The sound wavefront is deformed from a concentric sphere to a spheroid. Therefore, if the sound source and the radar are placed at the same point, the orthogonality condition is satisfied only when the radar antenna is pointed into the zenith direction. In a real atmosphere, the background winds affect the propagation of sound waves. For example, when the horizontal wind speed increases from the value on the Earth's surface at a certain rate with increasing height, the shape of the sound wave surface is such that the principal axis of the spheroid is tilted. If this happens, the orthogonality condition cannot be met even if the radar antenna is pointed in the vertical direction.

We employed the 3-D ray-tracing method to estimate the sound wavefronts, assuming the realistic profiles of the temperature and the background horizontal wind velocity. Then, we steered the antenna beam to satisfy the orthogonality condition (Eq. 3), which depends on the relative geometric arrangement between the radar and the acoustic source. When a sound source is installed in the windward direction with respect to the radar, the antenna beam pointed in the windward direction is the optimal condition.

The RASS echo can be expected when the returned radio signal points to the center of the WPR antenna. To infer the allowance of the RASS echo detection, we assume that the returned echo falls in the area within some distance from the antenna center. We define the distance between the RASS echo from the antenna center as the index of the RASS echo intensity.

Assuming the wind velocity profiles in Fig. 1 observed with EAR at 00:00 LT on September 3, 2016, we conducted the 3-D ray-tracing of acoustic wavefronts. Because the wind velocity above about $11 \mathrm{~km}$ was not fully obtained by EAR, we refer to the nearby radiosonde data archived at NOAA (https://esrl.noaa.gov/) for the wind velocity profiles above $11 \mathrm{~km}$. The shape of the acoustic wavefronts is nearly concentric, but the spacing between the wavefronts becomes shorter as they propagate higher because of the decrease in the sound speed associated with the temperature decrease.

The RASS echoing region of the acoustic wavefronts was determined as in Fig. 2, where the shading gradation

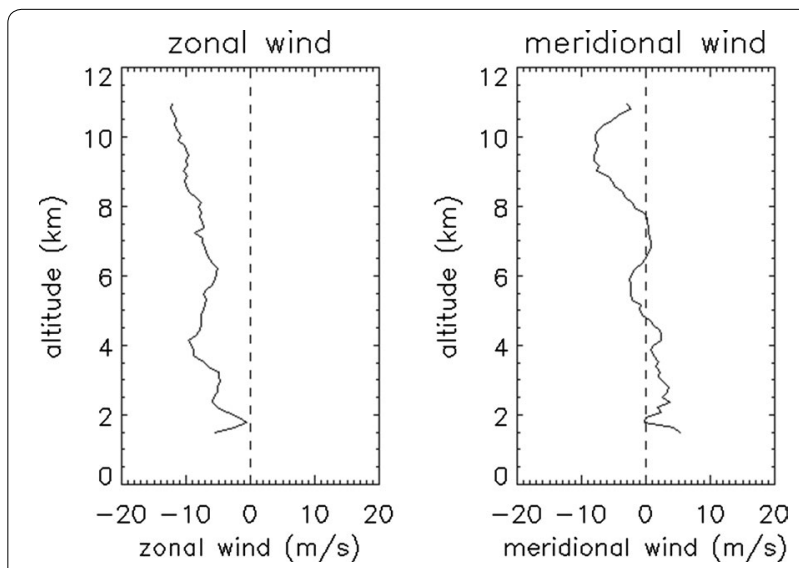

Fig. 1 Eastward (left) and northward (right) wind velocity profiles observed with EAR at 00:00 LT on September 3, 2016 


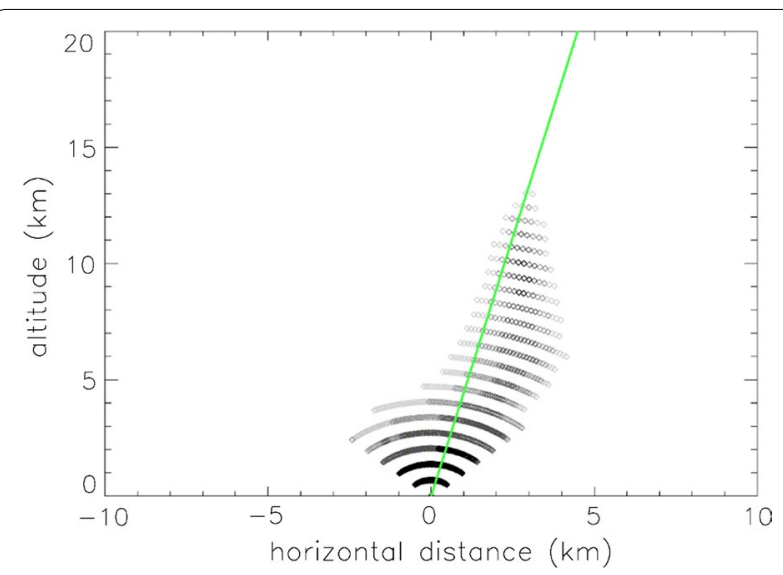

Fig. 2 Distribution of the RASS echoing region that satisfies the Bragg condition. The shading depth is changed as a function of the distance between the return point of the RASS echo on the ground and the center of the EAR antenna. The figure shows four levels of the shading for a distance up to $80 \mathrm{~m}$ with a step of $20 \mathrm{~m}$. The green line indicates the antenna beam with the zenith angle at $13^{\circ}$

is changed, depending on the distance of the echo return point from the antenna center every $20 \mathrm{~m}$. The straight line corresponds to the antenna beam direction that can detect RASS echoes up to about $13 \mathrm{~km}$, although the echo power may be reduced at around $7 \mathrm{~km}$. The asymmetry of the wavefronts can be clearly recognized, which was caused by the zonal winds. A 3-D plot of the RASS echoing region is shown in Fig. 3. The five blue lines indicate the antenna beam directions used in the conventional five-beam method for EAR-RASS experiments in 2001-2005, which did not effectively detect the RASS echoes. Meanwhile, the appropriately steered antenna

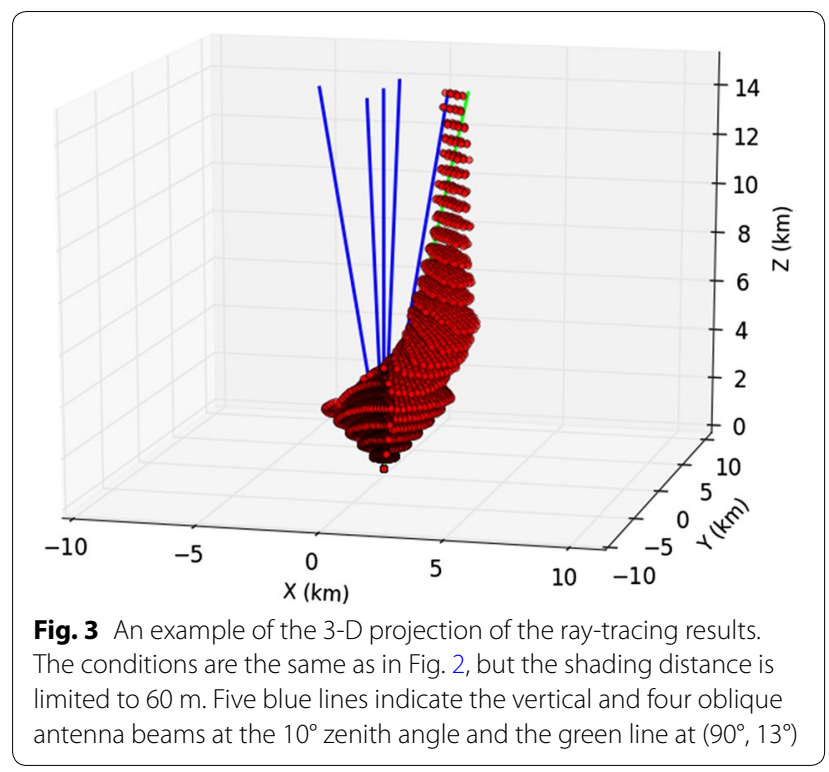

beam, shown by the green line in Fig. 3, successfully observed the RASS echoes in a wider height range.

During the EAR-RASS campaigns, we checked the variations in the wind fields about every hour and repeated the 3-D ray-tracing computation. Then, the antenna beam directions were changed appropriately, if necessary. When the EAR wind data were not available, we referred to the operational radiosonde data taken at Singapore and Kuala Lumpur at 00:00 and 12:00 UT. As these stations are about $400 \mathrm{~km}$ away from EAR, details of the wind velocity fluctuations may not fully represent the wind field over the EAR site.

The straight ray path of the RASS echoes does not necessarily return to the antenna center, and only a part of the antenna area is illuminated by the RASS echo. Then, the effective beam direction becomes slightly different from the antenna boresight, which could produce an error in the estimation of the radial wind velocity (May et al. 1996).

Here, we assume that the vertical beam is employed to detect the RASS echo whose ray path returned to the point $50 \mathrm{~m}$ away from the antenna center. The effective zenith angle of the antenna beam is not zero anymore, becoming about $0.017^{\circ}$ and $0.005^{\circ}$ at 1.5 and $5 \mathrm{~km}$ altitude, respectively. Then, the background radial wind measurement is contaminated by the projection of the horizontal winds. Assuming the horizontal wind velocity is 3 and $10 \mathrm{~m} \mathrm{~s}^{-1}$ at 1.5 and $5 \mathrm{~km}$, respectively, the error in the radial wind velocity can be estimated at about $0.05 \mathrm{~m} \mathrm{~s}^{-1}$ at both altitudes, which corresponds to a temperature error of about $0.08 \mathrm{~K}$. Therefore, the anticipated error by May et al. (1996) seems to be insignificant.

\section{EAR-RASS experiments Outline of RASS experiments}

Basic specifications of EAR are shown in Table 1. EAR is equipped with a quasi-circular active phased array of 560 three-element Yagi antennas and has a diameter of

\begin{tabular}{|c|c|}
\hline Location & $100.32^{\circ} \mathrm{E}, 0.2^{\circ} \mathrm{S}, 865 \mathrm{~m} \mathrm{MSL}$ \\
\hline Active phased array antenna & $\begin{array}{l}110 \mathrm{~m} \text { in diameter with } 560 \text { 3-ele- } \\
\text { ment Yagi }\end{array}$ \\
\hline Operating frequency & $47 \mathrm{MHz}$ \\
\hline Peak transmitting power & $100 \mathrm{~kW}$ \\
\hline Shortest pulse width & $1 \mu \mathrm{s}$ \\
\hline Height resolution & $150 \mathrm{~m}$ \\
\hline Antenna beam steering & $\begin{array}{l}\text { Any direction within } 30^{\circ} \text { from the } \\
\text { zenith }\end{array}$ \\
\hline Effective antenna beam width ( $3 \mathrm{~dB}$ ) & $3.4^{\circ}$ \\
\hline
\end{tabular}


approximately $110 \mathrm{~m}$ (Fukao et al. 2003). The peak transmitting power is $100 \mathrm{~kW}$, which is $1 / 10$ of the MU radar, with a maximum duty factor of $5 \%$. Therefore, the sensitivity of EAR is somewhat poorer than the MU radar. The maximum echoing height varies depending on the refractive index turbulence intensity and the background conditions. During our RASS experiments, the effective height range of the turbulence echoes was mostly limited to $10-11 \mathrm{~km}$, while the lowest height of the EAR wind measurements is about $1 \mathrm{~km}$ above the ground because of the blanking of a receiver by the transmitted pulse.

Here, the fundamental procedure and the observation parameters of the EAR-RASS experiments are summarized. First, we conducted the 3-D ray tracing to the acoustic wave shape, referring to the updated wind velocity profiles with EAR and the climatological temperature profiles from archived radiosonde results. Then, we selected antenna beam directions that can cover a wide height range for RASS echoes. The frequency range of the FM-chirped acoustic signal was also appropriately adjusted (Masuda et al. 1992). Once RASS experiments began, the performance of the RASS echo acquisition was checked, and the observations parameters, especially the antenna beam directions, were changed every few hours.

We interleaved the conventional wind velocity measurements with turbulence echoes and RASS measurements. The former is necessary to determine the wind velocity variations, which can be combined with the RASS temperature data for studies of meteorological phenomena. In addition, real-time wind information is important for the 3-D ray tracing of the sound waves as well as the compensation of radial wind velocity from the apparent sound speed. Tables 2 and 3 show system parameters for both turbulence and RASS experiments, respectively.

Considering that IPP was $400 \mu$ s and the number of coherent integrations was 64, one set of Doppler spectra

Table 2 Radar parameters for the turbulence echo measurements with EAR

\begin{tabular}{|c|c|}
\hline Range resolution & $150 \mathrm{~m}$ \\
\hline Minimum height & $1050 \mathrm{~m}$ \\
\hline $\begin{array}{l}\text { Bean direction (Azimuth, Zenith } \\
\text { angle) }\end{array}$ & $\begin{array}{l}\left(0^{\circ}, 0^{\circ}\right),\left(0^{\circ}, 10^{\circ}\right),\left(90^{\circ}, 10^{\circ}\right),\left(180^{\circ}, 10^{\circ}\right), \\
\left(270^{\circ}, 10^{\circ}\right)\end{array}$ \\
\hline IPP (beam steering interval) & $400 \mu \mathrm{s}$ \\
\hline Number of coherent integration & 64 \\
\hline Number of incoherent integration & 4 \\
\hline Number of FFT points & 128 \\
\hline Pulse code & $\begin{array}{l}\text { 16-bit optimum code of Spano and } \\
\text { Ghebrebrhan (1996) }\end{array}$ \\
\hline Number of height samples & 150 \\
\hline Duration & $65.5 \mathrm{~s}$ \\
\hline
\end{tabular}

Table 3 Radar parameters for the RASS measurements with EAR

\begin{tabular}{ll}
\hline Range resolution & $150 \mathrm{~m}$ \\
Minimum height & $1050 \mathrm{~m}$ \\
Beam steering & $\begin{array}{c}5 \text { beams, depending on 3-D ray- } \\
\text { tracing results }\end{array}$ \\
$\begin{array}{ll}200 \mu \mathrm{s} \\
\text { IPP (beam steering interval) }\end{array}$ & 16 \\
Number of coherent integration & 5 \\
Number of incoherent integration & 512 \\
Number of FFT points & $8-$ bit optimum code of Spano and \\
Pulse code & Ghebrebrhan (1996) \\
Number of height samples & 150 \\
Duration & $41.0 \mathrm{~s}$ \\
\hline
\end{tabular}

for five beams was obtained every $16.4 \mathrm{~s}$. The range of the Doppler spectrum was $3.9 \mathrm{~Hz}$, and the frequency resolution was $0.03 \mathrm{~Hz}$. So, the maximum radial wind velocity ranged up to $12.5 \mathrm{~m} \mathrm{~s}^{-1}$ with a resolution of $0.10 \mathrm{~m} \mathrm{~s}^{-1}$. We take this resolution as the nominal measurement error (r.m.s. standard deviation) of the radial wind velocity measurements with EAR. Assuming the sound speed can be determined with the same r.m.s. $\left(0.1 \mathrm{~m} \mathrm{~s}^{-1}\right)$, we can estimate the accuracy of the RASS temperature to be about $0.17 \mathrm{~K}$ on the ground and about $0.13 \mathrm{~K}$ near the tropopause.

We derived the horizontal wind velocity by combining a pair of radial winds in either the east-west or northsouth directions at a zenith angle of $10^{\circ}$. Assuming the error distribution is the same for the beam pair, we can estimate the error of the resulting horizontal wind velocity to be $\sqrt{2 \times 0.1^{2}} / 2 \sin 10^{\circ}=0.407 \mathrm{~m} \mathrm{~s}^{-1}$.

The sound speed in the troposphere normally ranges from 270 to $350 \mathrm{~m} \mathrm{~s}^{-1}$, which is far away from the zero Doppler shift. Thus, the major part of the Doppler spectrum is not used for RASS measurements. We employed an additional receiver channel for RASS, which can shift the frequency of the intermediate frequency (IF) signal by about $100 \mathrm{~Hz}$ so as to move the RASS signal toward the center of the Doppler spectrum. Because a small frequency drift in this offset is anticipated, we analyzed the exact offset value by investigating the frequency shift of the ground clutter.

We added another observation mode for the turbulence echoes by steering the antenna beam into the same directions as the RASS mode. However, we did not apply a frequency shift in the receiver channel. Thus, we measured directly the radial wind velocity in the beam direction of RASS echoes. Interleaving the pair of RASS and turbulence echo modes took $113 \mathrm{~s}$, increasing to about $181 \mathrm{~s}$ with the addition of another mode for the radial wind velocity measurements. 


\section{Acoustic transmitter}

Considering the resonance condition for RASS, we needed an efficient acoustic transmitter at $80-110 \mathrm{~Hz}$, corresponding to the radar wavelength of $6.38 \mathrm{~m}$. We employed a horn speaker designed by Adachi (1996), which was used for the MU radar and the Gadanki MST radar. Figure 4 shows the design of the horn speaker. Two sets of woofer speakers (Electro-Voice DL-15X or Kappa Pro 15A) with a nominal output of $400 \mathrm{~W}$ were installed in the horn.

In addition, we made a simple acoustic transmitter using a subwoofer speaker with an enclosure (TOA, FB120B). We placed two sets of subwoofers in a wooden box with the front facing down. The bottom of the box is open. Sound waves were emitted downward, reflected on the ground, and transmitted upward to the sky.

The sound source is generated by a control PC, connected to four preamplifiers located inside the control building. Two outputs from each preamplifier are fed to a power amplifier in the antenna field. As the power amplifier has two outputs, a total of 16 speakers can operate.

Figure 5 shows the location of these acoustic transmitters. We put four sets of high-power speakers in the antenna center, and an additional two sets were placed northwest and southwest of the antenna. Two sets of subwoofer speakers were located east of the antenna, and one subwoofer speaker each was placed north and south of the antenna. After several test experiments, we finalized the setup of all speakers on May 31, 2016.
Assuming a temperature range in the troposphere from 25 to $-90{ }^{\circ} \mathrm{C}$, the corresponding sound speed ranges from 346 to $271 \mathrm{~m} \mathrm{~s}^{-1}$. As the radar wavelength is $6.38 \mathrm{~m}$, the acoustic frequency ranges from 108.5 to $85.0 \mathrm{~Hz}$. We used a WAVE file for the FM-chirped signal sweeping from 110 to $85 \mathrm{~Hz}$ in $2 \mathrm{~s}$. The control PC produced this FM-chirped signal every $10 \mathrm{~s}$.

\section{Observation periods of EAR-RASS experiments}

We repeated the EAR-RASS experiments eight times in 2016 as summarized in Table 4, where the local time in Indonesia (LT) precedes UT by seven hours. During the first three periods, the sweep range of the FM-chirped acoustic signal was set at $115-90 \mathrm{~Hz}$ to measure the temperature up to $14 \mathrm{~km}$. During period (3), we tested several different acoustic frequency ranges. After period (4), we expanded the range to $115-85 \mathrm{~Hz}$, aiming to reach the tropopause. For period (8), two sets of signals with a duration of $2 \mathrm{~s}$ at $110-90 \mathrm{~Hz}$ and $95-75 \mathrm{~Hz}$ were used, interleaving every $10 \mathrm{~s}$.

Climatological results of the wind fields over Koto Tabang from an earlier EAR dataset indicate that the meridional winds are normally weak, while the zonal winds sometimes exceed about $30 \mathrm{~m} \mathrm{~s}^{-1}$. In particular, both zonal and meridional winds were weak in April; then, the vertical beam could capture the RASS echo in the entire troposphere. On the other hand, zonal winds were stronger in October-December. Throughout the year, the zonal winds were westward at $10-14 \mathrm{~km}$, so the

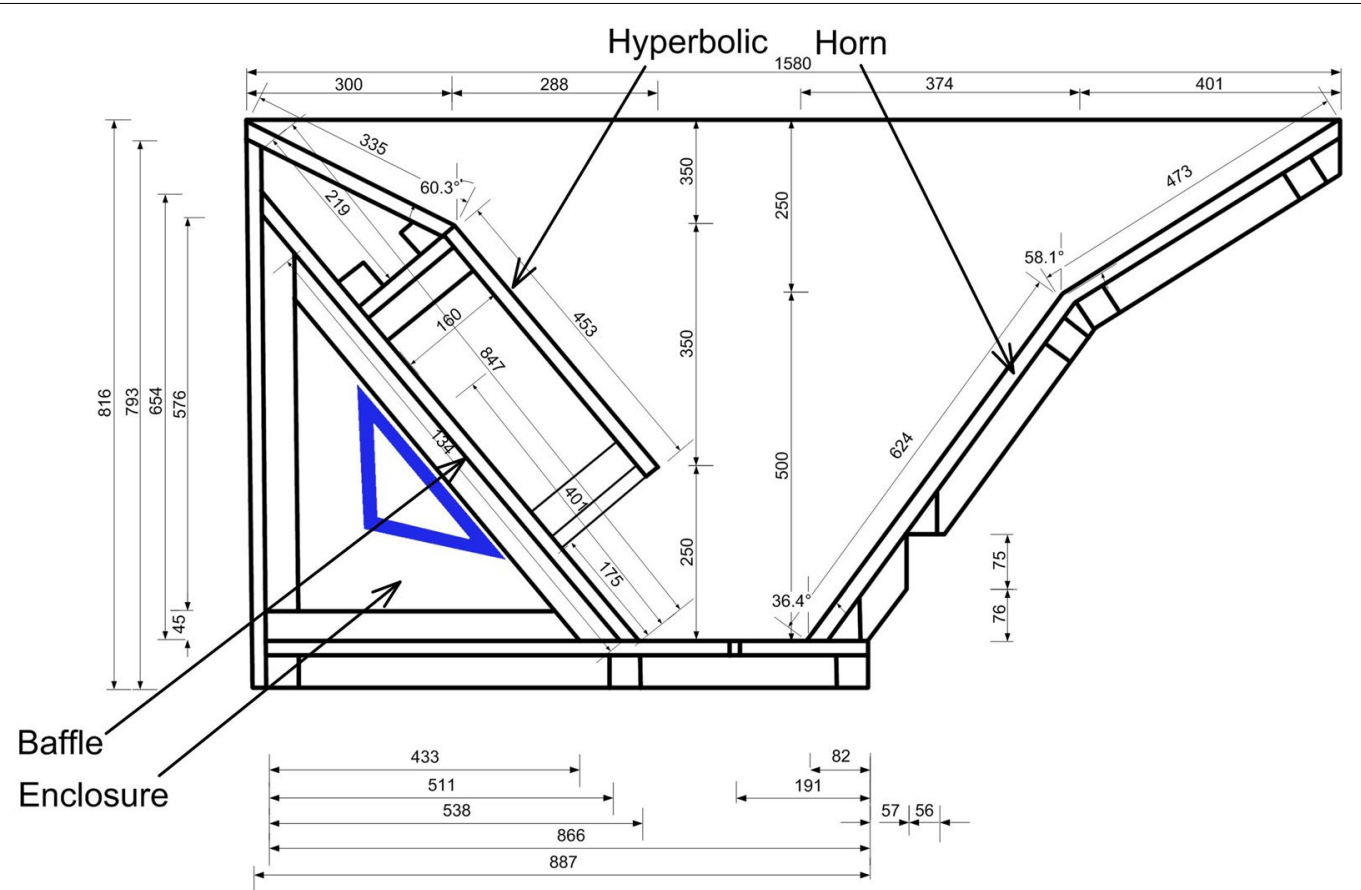

Fig. 4 Cross section of the horn speaker (Adachi 1996). A blue triangle indicates a woofer speaker that is commercially available 


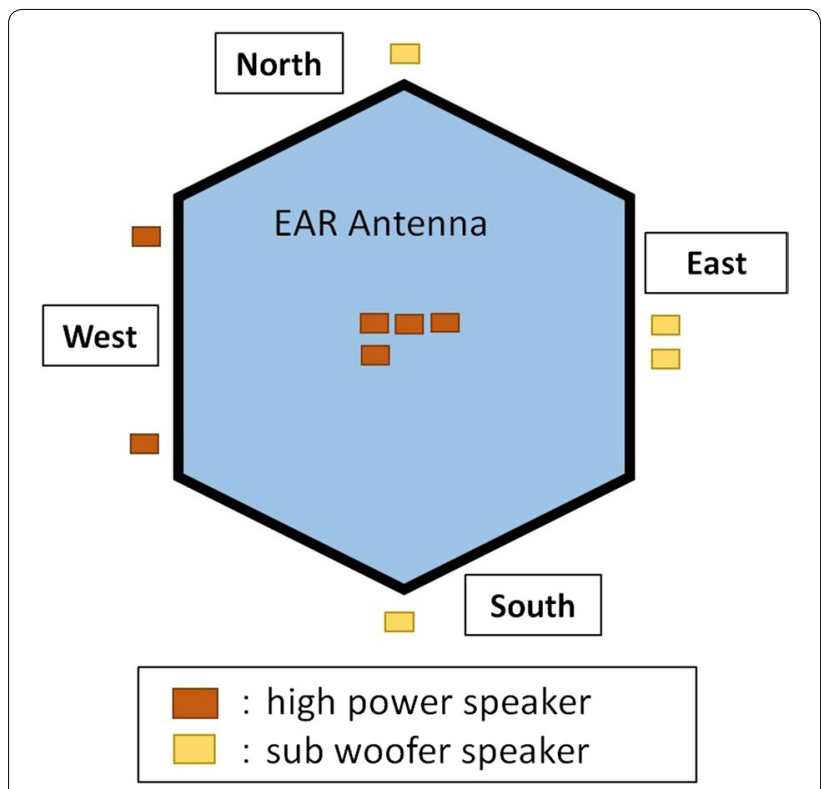

Fig. 5 Location of acoustic speaker for EAR-RASS. Type (A) is a highpower horn speaker, and type (B) is a subwoofer speaker

antenna beam was mostly steered toward the east for the RASS experiment.

During the observation periods (1) and (2), we employed the standard five-beam method with the zenith angle at $10^{\circ}$, because RASS echoes were expected by the vertical beam. For other periods after April 30, 2016, we selected the beam directions referring to the 3-D ray tracing on a real-time basis.

For the turbulence echo, we apply a fitting to the observed Doppler spectrum assuming the Gaussian distribution. We also adopted a Gaussian fitting for the RASS echo. As the height profile of the sound speed is roughly known a priori, we limited the range of the mean Doppler shift from a climatological profile, where the temperature decreases at $6.5 \mathrm{~K} \mathrm{~km}^{-1}$ from the surface up to the tropopause at $17 \mathrm{~km}$. Then, the temperature increases in the stratosphere at $2 \mathrm{~K} \mathrm{~km}^{-1}$. The threshold of temperature variability was set at 15 and $20 \mathrm{~K}$ in the troposphere and stratosphere, respectively, which is much larger than the actual temperature fluctuations.

Figure 6 shows an example of the Doppler spectrum in two different formats: power spectra at each range gate (top) and a contour plot (bottom), which were obtained at 00:14 LT on September 3, 2016 with the antenna beam at the azimuth and zenith angles at $90^{\circ}$ and $13^{\circ}$, respectively. It is noteworthy that a positive Doppler shift indicates a target moving away from the radar, which is opposite to the conventional definition of the Doppler shift. The RASS echo was strong up to about $5 \mathrm{~km}$, becoming weaker at $5-10 \mathrm{~km}$ with a clear echo again at $10-13 \mathrm{~km}$. These spectra correspond to the 3-D ray-tracing shown in Fig. 2, indicating that the ray-tracing method properly predicted the RASS echoing region.

\section{Location of acoustic speakers}

We were interested in determining which speakers on the antenna field were effective in producing the RASS echoes. During campaign period (4), shown in Table 4, we selected a calm condition without significant wind variations. We first operated all speakers, and we stopped the four speakers in the antenna center from 14:37 LT on May 31 so that only the speakers outside the antenna were running. Then, we turned on the central speakers one by one at 14:45, 14:48, 14:56, and 15:02 LT.

Using the wind velocity profiles in Fig. 7 observed with EAR at 14:30 LT on May 31, 2016, we conducted a 3 -D ray-tracing analysis, and we show in Fig. $8 \mathrm{a}, \mathrm{b}$ the cross section at an azimuth angle of $60^{\circ}$ for the speakers located in the antenna center and east side, respectively. Note that the wind data were limited up to about $11 \mathrm{~km}$, so the ray-tracing plots may not be reliable above $11 \mathrm{~km}$.

Table 4 Observation periods of EAR-RASS in 2016

\begin{tabular}{|c|c|c|c|c|c|c|c|c|}
\hline \multirow[t]{2}{*}{ No } & \multicolumn{3}{|l|}{ Start } & \multicolumn{3}{|l|}{ Stop } & \multirow{2}{*}{\multicolumn{2}{|c|}{$\begin{array}{l}\text { Sweep range } \\
\text { of FM chirp }(\mathrm{Hz})\end{array}$}} \\
\hline & Month & Day & LT & Month & Day & LT & & \\
\hline (1) & Feb & 1 & $12: 00$ & Feb & 4 & 13:00 & 115 & 90 \\
\hline (2) & Mar & 24 & $16: 00$ & Mar & 27 & 15:00 & 115 & 90 \\
\hline (3) & Apr & 30 & $16: 00$ & May & 1 & $12: 00$ & 115 & 90 \\
\hline (4) & May & 29 & $14: 00$ & Jun & 2 & $16: 00$ & 115 & 85 \\
\hline (5) & Jun & 27 & $9: 00$ & Jul & 1 & $15: 00$ & 115 & 85 \\
\hline (6) & Aug & 5 & 9:00 & Aug & 6 & $15: 00$ & 115 & 85 \\
\hline (7) & Aug & 29 & $8: 00$ & Sep & 3 & $6: 00$ & 115 & 85 \\
\hline \multirow[t]{2}{*}{ (8) } & Nov & 21 & $14: 00$ & Nov & 24 & $16: 00$ & 110 & 90 \\
\hline & & & & & & & 95 & 75 \\
\hline
\end{tabular}




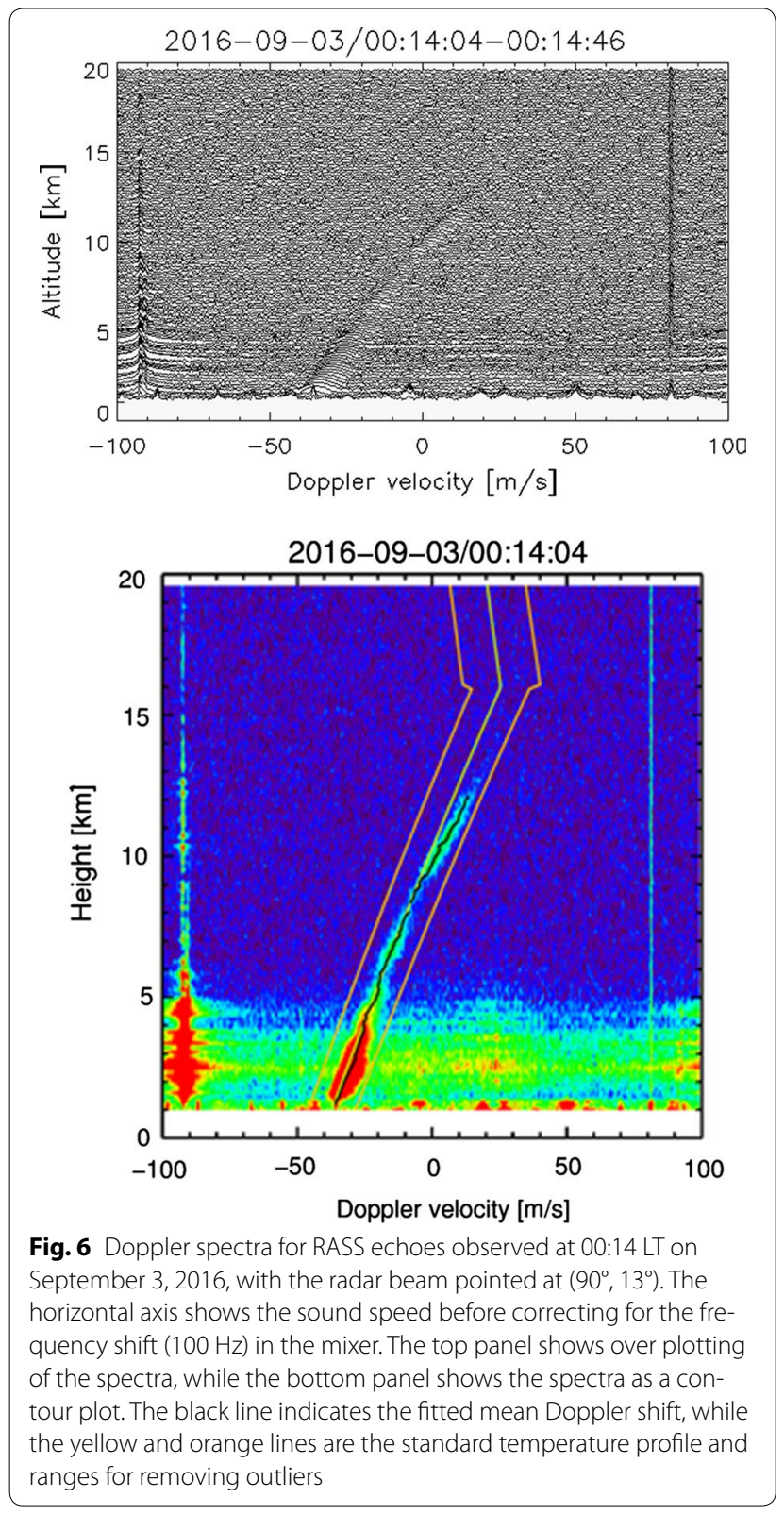

Figure 9 shows the RASS echo power measured with the beam at $\left(60^{\circ}, 10^{\circ}\right)$ at $1.64,4.48$, and $7.92 \mathrm{~km}$ altitudes.

When all the speakers were turned on at the beginning of the period, the RASS echo intensity was the largest at $1.64 \mathrm{~km}$, diminishing at $4.48 \mathrm{~km}$, and again becoming stronger at $7.92 \mathrm{~km}$, consistent with the ray-tracing results. The speakers in the antenna center were turned on one by one, whose timing is indicated by the dashed lines in Fig. 9. Although the echo intensity showed considerable fluctuations, it increased stepwise according to
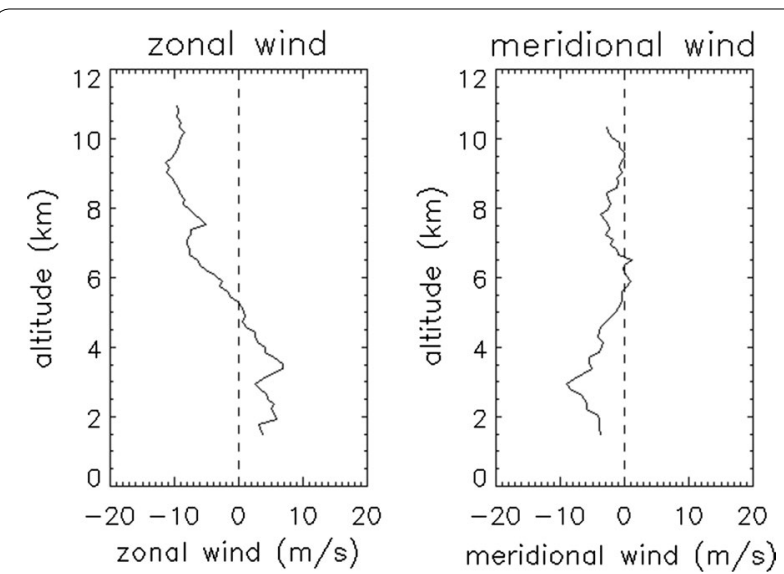

Fig. 7 Eastward (left) and northward (right) wind velocity profiles observed with EAR at 14:30 LT on May 31, 2016
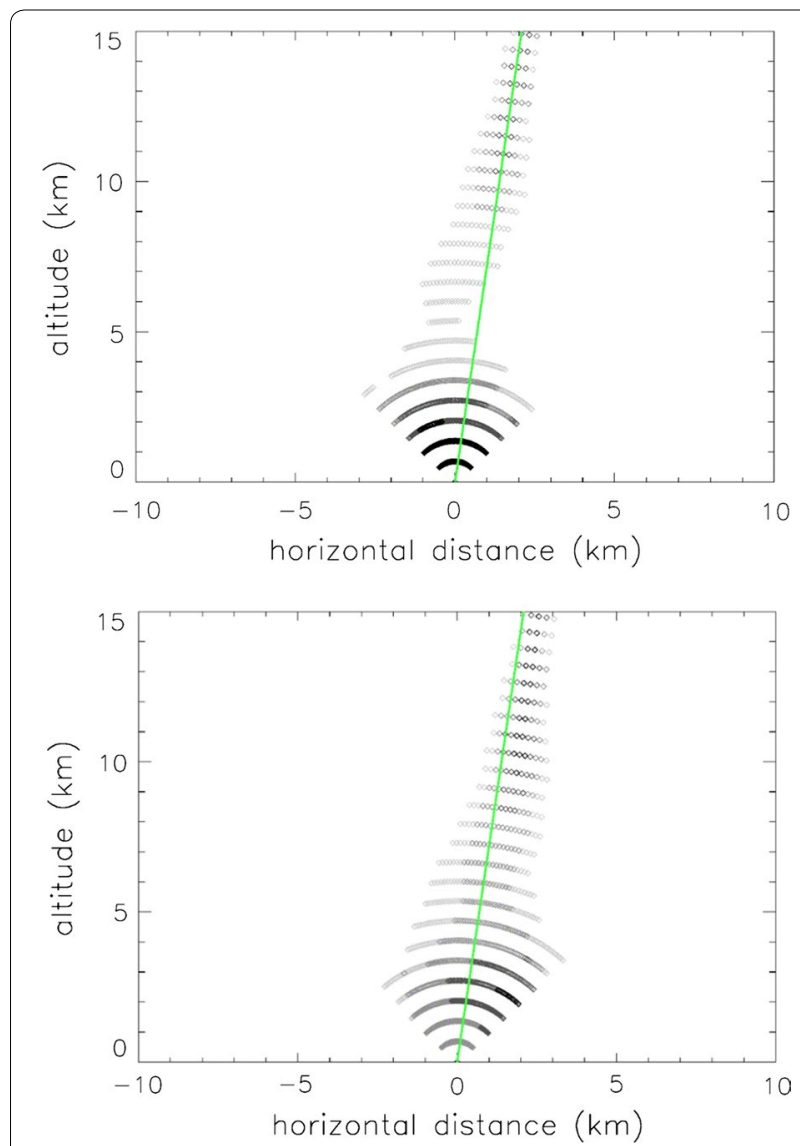

Fig. 8 Cross sections of the ray-tracing results with an azimuth angle of $60^{\circ}$, assuming the background wind velocity profiles shown in Fig. 7, for the acoustic source located in the center of the EAR antenna (top panel) and the speakers located $50 \mathrm{~m}$ away from the antenna center toward east (bottom panel) 


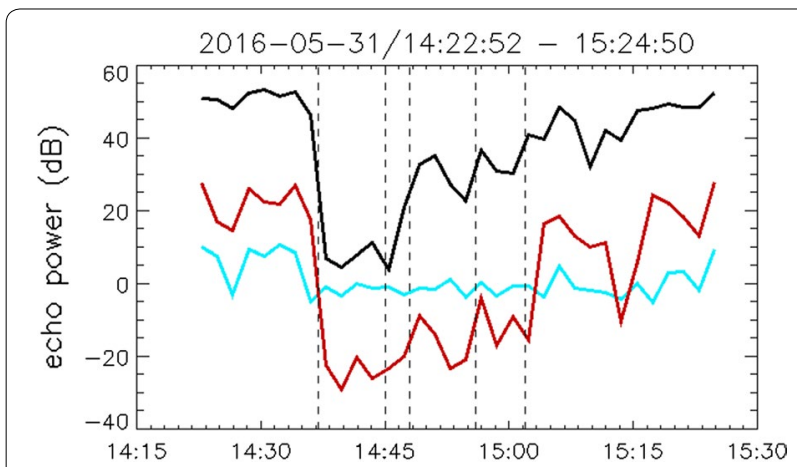

Fig. 9 Time variations of the RASS echo power at $1.64 \mathrm{~km}$ (black), $4.48 \mathrm{~km}$ (blue), and $7.92 \mathrm{~km}$ (red) from 14:22 to 15:24 LT on May 31, 2016. Operation of the speakers was changed at the timing of the vertical dashed lines (see text)

the number of speakers at 1.64 and $7.92 \mathrm{~km}$. The echo power finally returned to a similar value after 15:02 LT. Thus, the RASS echo power was basically in proportion to the number of the speakers in the antenna center. Meanwhile, at $4.48 \mathrm{~km}$, the echo power was nearly constant during this experiment, indicating that the speakers outside the antenna contributed to produce RASS echoes. These outside speakers were also effective at $1.64 \mathrm{~km}$, but not at $7.92 \mathrm{~km}$, probably because the sound output was not large enough to reach higher altitudes.

To summarize, placing more speakers within the antenna area is recommended, but those outside the antenna also contributed to RASS echoes, depending on the background wind conditions.

\section{Sweep range of FM-chirped signal}

During experiment (4) from May 29 to June 2, we tested the effects of the sweep range of the acoustic frequencies. By selecting the sweep range from 90 to $115 \mathrm{~Hz}$, the height range from the ground up to $14 \mathrm{~km}$ is covered. We narrowed the range to $90-100 \mathrm{~Hz}$ from 16:23 LT on May 31, which corresponds to a height range above $6.6 \mathrm{~km}$. Then, after this change of the acoustic frequency range, RASS echoes disappeared below about $6.5 \mathrm{~km}$ in Fig. 10, and the RASS echo power above about $7.5 \mathrm{~km}$ became stronger.

Time variations of the RASS echo power are plotted in Fig. 11 at 8.67, 8.97, and $9.26 \mathrm{~km}$, where the sweep range was switched at 16:23 LT as indicated by the straight line. When the sweep rate became slower, the sound on the same frequency was emitted 2.5 times longer after 16:23 LT. Thus, we expected the increase in the echo power to be $2.5^{2}=8.0 \mathrm{~dB}$. We calculated the arithmetic mean of the RASS echo power during 16:12-16:20 LT and 16:25-16:33 LT, which were the periods before and after the change in the acoustic signals. The mean value increased by $7.6 \mathrm{~dB}$ from 10.2 to $17.8 \mathrm{~dB}$ at $8.67 \mathrm{~km}$. The increase was $16.5 \mathrm{~dB}$ from -7.9 to $8.6 \mathrm{~dB}$ at $8.97 \mathrm{~km}$ and $14.0 \mathrm{~dB}$ from -16.9 to $-2.9 \mathrm{~dB}$ at $9.26 \mathrm{~km}$. Figure 10 shows that the RASS echo was most continuous at $8.67 \mathrm{~km}$ among the three altitudes, where the increase in the RASS echo power $(7.6 \mathrm{~dB})$ was consistent with the theoretical prediction $(8 \mathrm{~dB})$.

It is recognized that the sweep range, which is related to the number of wave acoustic cycles on a specific acoustic frequency, affected the RASS echo power.

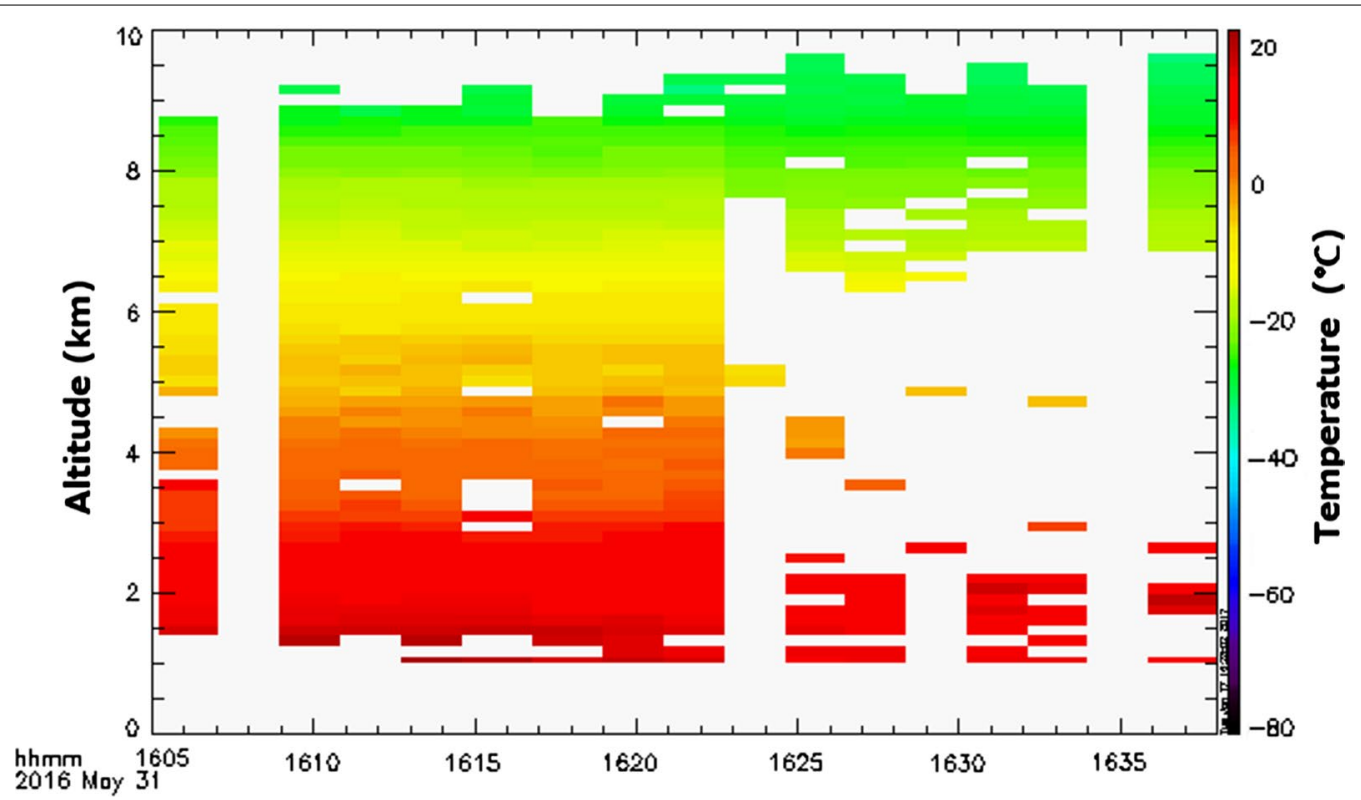

Fig. 10 Time and height variations of the temperature observed with EAR-RASS from 16:05 to 16:38 LT on May 31, 2016. Sweep range of the FMchirped acoustic signals was changed at 16:23 LT (see text) 


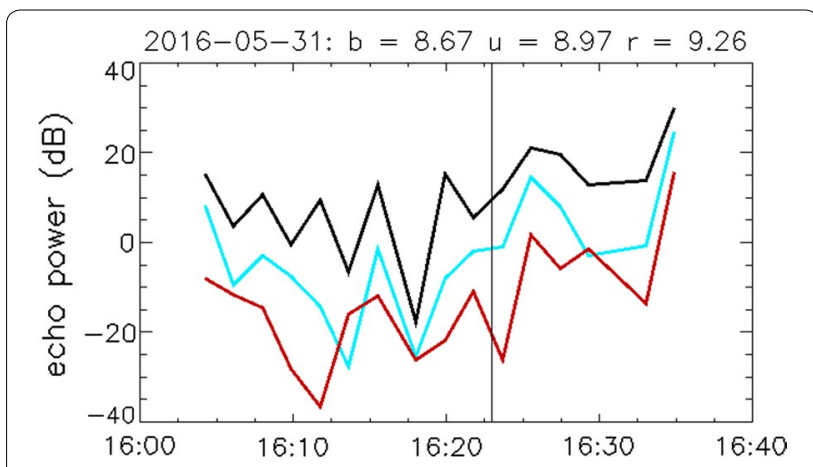

Fig. 11 Time variations of the RASS echo intensity from 16:05 to 16:58 on May 31, 2016, at 8.67 km (black), 8.97 km (blue), and $9.26 \mathrm{~km}$ (red) altitudes. The sweep range of the acoustic signal was changed at the timing of the vertical line

Emitting combinations of several FM-chirped acoustic pulses with different sweep ranges is useful for obtaining strong RASS echoes.

\section{Compensation of radial wind velocity}

WPR observes the apparent sound speed; then, the true sound speed is obtained by compensating for the radial wind velocity. Referring the temperature estimation using Eq. (4), a radial wind velocity of $1 \mathrm{~m} \mathrm{~s}^{-1}$ would produce an error of 1.7 and $1.4 \mathrm{~K}$ near the ground and at $16 \mathrm{~km}$ altitude, respectively.

We can obtain the radial wind velocity in the direction of the RASS beams by composing it from the vertical and two horizontal wind velocities. Assuming the error for the vertical and horizontal wind velocities to be 0.1 and $0.41 \mathrm{~m} \mathrm{~s}^{-1}$, respectively, the anticipated radial wind velocity error in the direction of RASS beams is about $0.32 \mathrm{~m} \mathrm{~s}^{-1}$. For the direct measurement of the radial wind velocity, the error is $0.1 \mathrm{~m} \mathrm{~s}^{-1}$. For the RASS experiment during period (7), the radial direction for RASS was $\left(90^{\circ}\right.$, $13^{\circ}$ ). We calculated two sets of radial wind velocities from 14:30 to 18:30 LT on August 30, calculated the r.m.s. difference, and averaged them at 3-7 km. The difference was $0.23 \mathrm{~m} \mathrm{~s}^{-1}$ for the radial wind velocity and $0.45 \mathrm{~K}$ for the temperature. Therefore, employing additional radial wind velocity measurements is recommended for improving the accuracy of the RASS temperature results.

\section{Results of the EAR-RASS measurements Temperature variations observed with EAR-RASS in August-September 2016}

We focus on the EAR-RASS results during campaign (7) from 08:56 LT on August 29 to 06:18 LT on September 3 . The original time resolution of the EAR-RASS $T$ profiles is about $3 \mathrm{~min}$ (181 s), as the three radar modes for the standard wind measurements, RASS, and the radial wind measurement were interleaved in the RASS beam directions. We launched radiosondes (VAISALA RS41SG) from the EAR site 12 times during campaign (7), as summarized in Table 5 . We selected the antenna beam directions that covered the widest RASS echoing height range, so the selected antenna beams varied time to time, as shown in Fig. 12. We determined the temperature for individual antenna beam directions from the fit of the Doppler spectra shown in Fig. 6.

Because the height coordinate of each beam is not uniform throughout the campaign, but depends on the zenith angle, we projected it to the standard height coordinate with the zenith angle at $10^{\circ}$. This is also used as the height coordinate of horizontal wind velocity with EAR. We applied a second-order inverse distance weighting interpolation (Wilks 2006) to obtain the $T$ profiles on the standard height coordinate. Due to some missing RASS echoes in a single profile, the nearest two RASS data points to the standard height were not always available for the interpolation. Therefore, we restricted the interpolation when the height difference (distance) from the standard coordinate point was within $0.6 \mathrm{~km}$. If the RASS results were missing for longer than this range, we skipped the interpolation. Thus, we obtained the $T$ profiles with the five RASS beams on the same height coordinate.

After the interpolation process, we applied the data screening of EAR-RASS $T$ profiles using radiosonde data for removing unrealistic values. The mean temperature profile is mostly stable in the tropical troposphere. So, we estimated the range of the temperature deviation, referring to earlier radiosonde data at the EAR site. An intensive campaign was conducted in December 2005, in which radiosondes were launched

Table 5 Radiosonde launch schedule during EAR-RASS campaign in August-September, 2016

\begin{tabular}{lllll}
\hline No & Date & $\begin{array}{l}\text { Launch time } \\
(\mathbf{L T}=\mathbf{7} \mathbf{h}+\mathbf{U T})\end{array}$ & $\begin{array}{l}\text { Maximum } \\
\text { altitude/balloon } \\
\text { burst (km) }\end{array}$ & $\begin{array}{l}\text { Comparison } \\
\text { of } \boldsymbol{N}^{\mathbf{2}} \text { with RASS }\end{array}$ \\
\hline 1 & Aug 30 & $08: 45$ & 27.0 & - \\
2 & Aug 30 & $11: 31$ & 26.0 & Yes \\
3 & Aug 30 & $15: 34$ & 25.8 & - \\
4 & Aug 31 & $07: 26$ & 26.2 & Yes \\
5 & Aug 31 & $11: 58$ & 27.1 & Yes \\
6 & Aug 31 & $19: 01$ & 24.7 & - \\
7 & Sep 01 & $07: 08$ & 26.7 & Yes \\
8 & Sep 01 & $10: 55$ & 24.4 & Yes \\
9 & Sep 01 & $15: 08$ & 18.4 & Yes \\
10 & Sep 02 & $07: 22$ & 25.6 & - \\
11 & Sep 02 & $11: 07$ & 24.4 & - \\
12 & Sep 02 & $18: 55$ & 20.8 & - \\
\hline
\end{tabular}



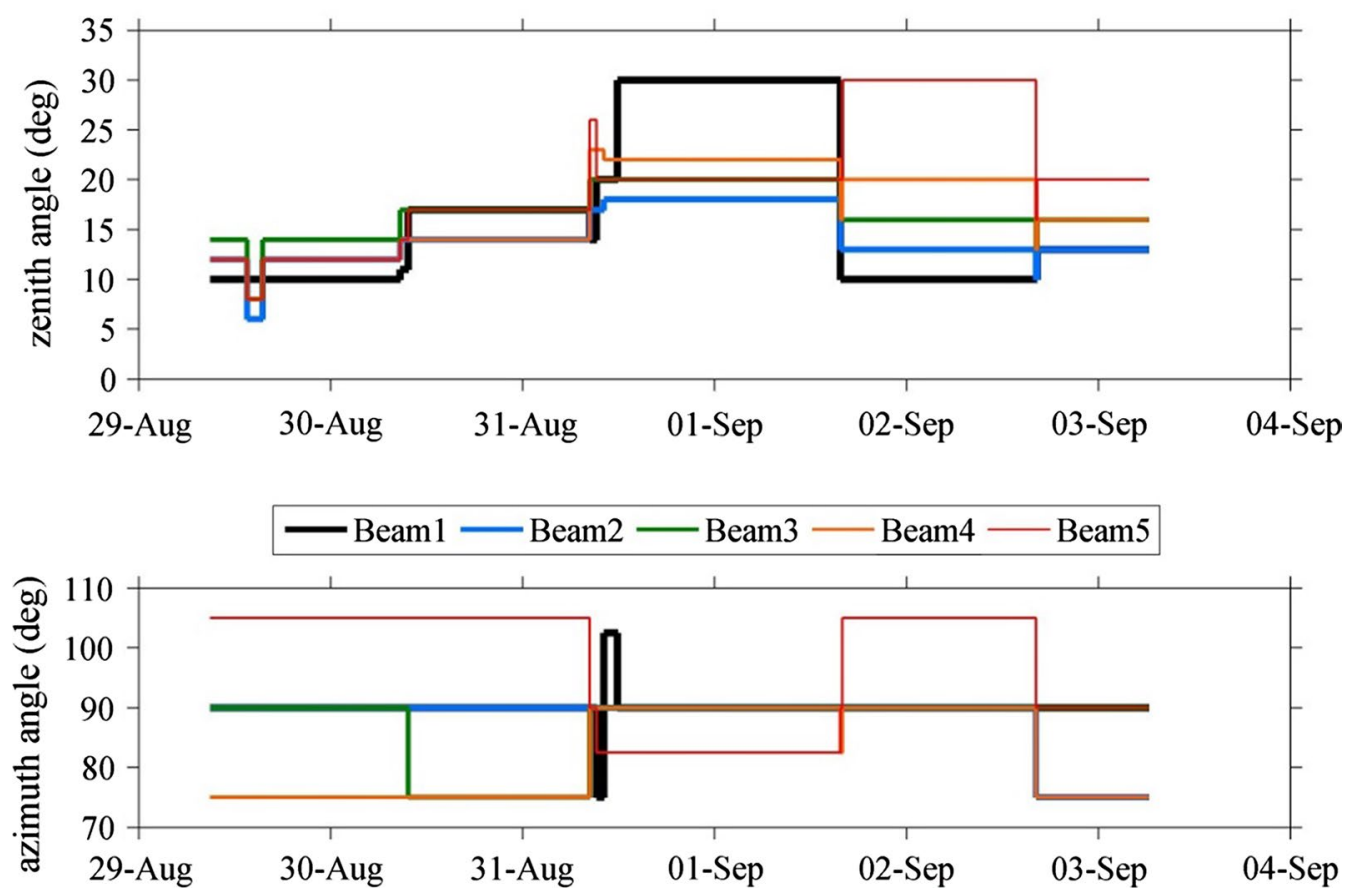

Fig. 12 Variation of zenith and azimuth angles during the EAR-RASS campaign from Aug 29 to Sep 3, 2016. Tick mark in the horizontal axis indicates 00:00 LT

with a time interval of $1 \mathrm{~h}$ on December 9-10, 12-13, 15-16, and 18-19, using three sets of radiosonde receivers (Ratnam et al. 2009). We estimated the range of the temperature variations with different balloon launch intervals of $1,2,4,6$, and $12 \mathrm{~h}$, as shown in Fig. 13. The standard deviation of $T$ profiles with

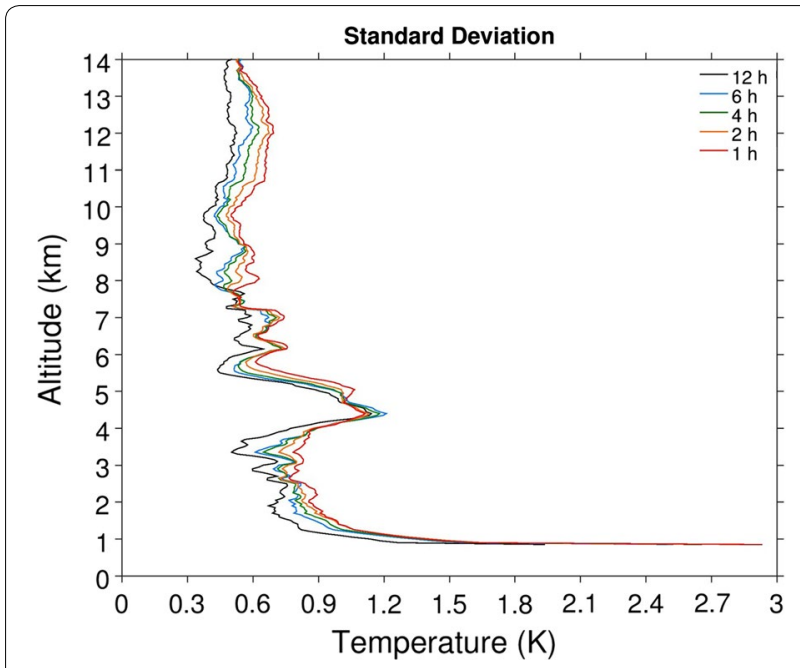

Fig. 13 Profiles of temperature perturbations (standard deviation) for different balloon launch intervals of 1, 2, 4, 6, and $12 \mathrm{~h}$ from the intensive radiosonde campaign in December 2005 at the EAR site 1-h time resolution ranged between 0.8 and $1.0 \mathrm{~K}$ at $1-4 \mathrm{~km}$, increasing to $1.2 \mathrm{~K}$ at $4-5 \mathrm{~km}$, and then decreasing to $0.6 \mathrm{~K}$ above $6 \mathrm{~km}$. We assumed that the EAR-RASS observation with a 3-min time resolution may have a larger standard deviation. So, we took three times the maximum deviation in Fig. 13, i.e., $1.2 \times 3=3.6 \mathrm{~K}$ as the threshold for removing outliers. We constructed a mean temperature profile from 12 radiosonde soundings during RASS campaign (7) in 2016. When the RASS values at each altitude deviated from this mean more than $3.6 \mathrm{~K}$, we rejected the RASS data as an erroneous determination. Note that the standard deviation of $T$ from 12 radiosonde profiles in 2016 was between 0.5 and $0.7 \mathrm{~K}$ in the troposphere up to $16 \mathrm{~km}$, much smaller than the above threshold.

At each height coordinate, we averaged all available data among the five beams every $10 \mathrm{~min}$, as the temperature is a scalar quantity. The time and height variations of the RASS temperature are plotted in Fig. 14 with time resolutions of $3 \mathrm{~min}$ (original time interval), $10 \mathrm{~min}$, and $1 \mathrm{~h}$. The data availability rate increased for longer time resolutions because of the interpolation along height and time averaging. With $10-\mathrm{min}$ time resolution, the temperature was obtained at $2-6 \mathrm{~km}$ with $50-80 \%$ availability, and the availability rate became $30-10 \%$ at $7-14 \mathrm{~km}$. The results in Fig. 14 are the basis of further data analysis. 

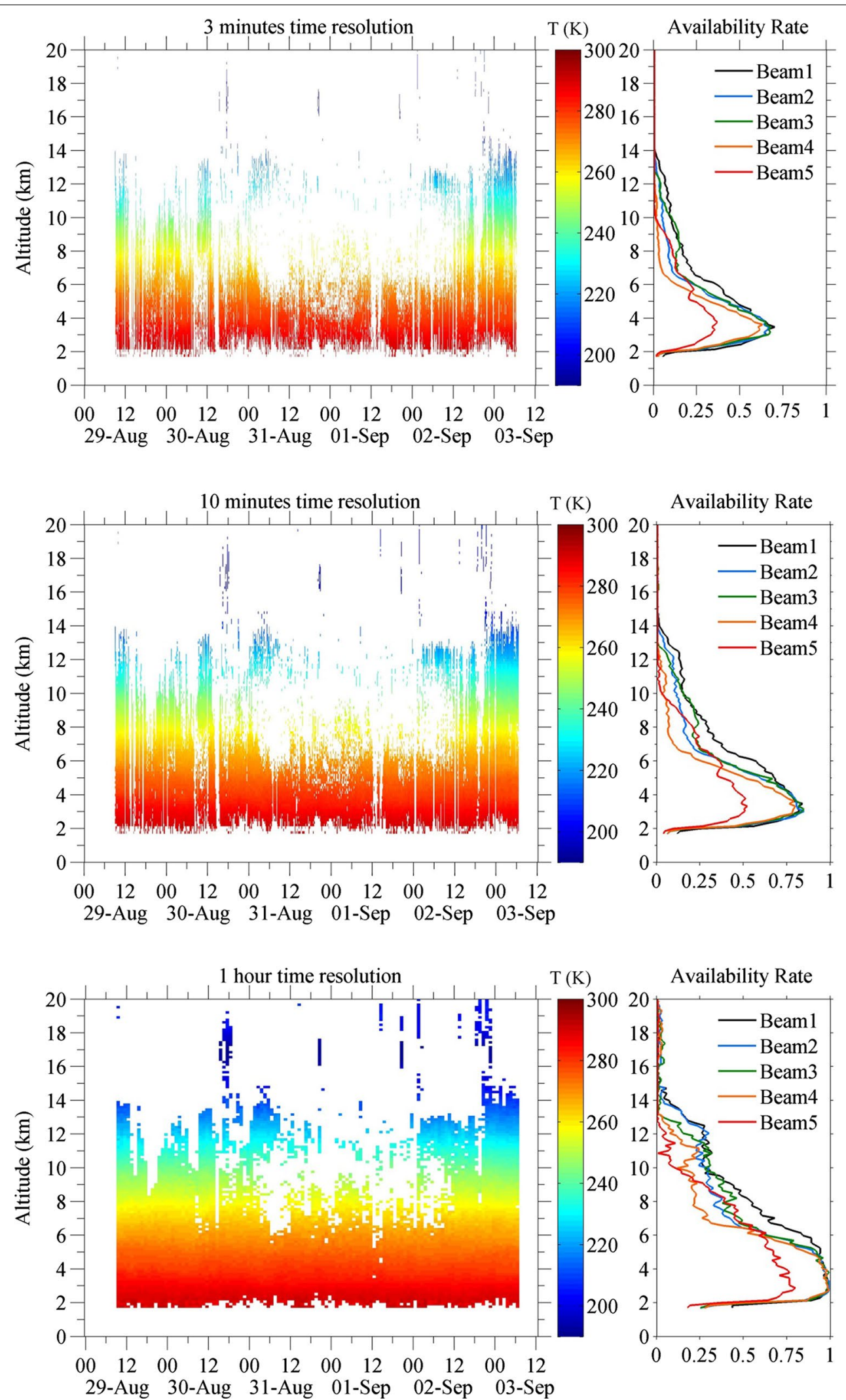

Fig. 14 Time and height plots of $T$ (left) and the data availability rate (right) for the original RASS data with 3-min resolution (top) and averaged results with $10 \mathrm{~min}$ (middle) and $1 \mathrm{~h}$ (bottom) averaging 


\section{Comparison between RASS and radiosonde}

For a few cases, we successfully obtained temperature profiles from RASS data up to the lapse rate tropopause at about $16 \mathrm{~km}$ as in Fig. 14. However, the radial wind velocity was not fully observed because of the limit of the EAR sensitivity, and the temperature results may not be accurate above about $11 \mathrm{~km}$.

Figure 15 shows the mean (virtual) temperature from the 12 radiosondes launched from August 30 to September 2, as listed in Table 5. We also averaged all RASS profiles with 10-min resolution as shown in Fig. 15. Because we set the threshold for the outlier of RASS data, referring to the radiosonde profiles, the RASS and radiosonde profiles are naturally consistent. However, the allowance range of the deviation is rather modest $(3.6 \mathrm{~K})$; thus, we investigated the consistency between the two measurements.

The middle panel in Fig. 15 shows the standard deviation from each mean profile, which was about $0.6 \mathrm{~K}$ for radiosondes and 1.0-1.5 K with RASS. The difference between the two profiles is plotted in the right panel in Fig. 15. A persistent discrepancy of about $0.9 \mathrm{~K}$ was evident for the entire height range. We suspect this difference (bias) may be attributed to the discrepancy in the height coordinates between the two measurements. The altitude of a radiosonde is determined with GPS above the MSL, while the height coordinate for EAR is inferred by estimating the system delay in the radar hardware. Although we adjusted the system delay (about $200 \mathrm{~m}$ ), comparing the EAR wind velocity profile with the simultaneous radiosonde, there seemed to remain an additional delay of about $100 \mathrm{~m}$. The standard deviation of the temperature difference from the mean values was estimated to be $0.4 \mathrm{~K}$, which we think is the implicit accuracy of RASS in comparison with a radiosonde.

\section{Temperature disturbance events}

Figure 16 shows the perturbation components of the RASS temperature with time resolutions of $10 \mathrm{~min}$ and $1 \mathrm{~h}$. Taking advantage of the continuous temperature monitoring with RASS, we plotted in Fig. 17 the time and height distribution of the Brunt Väisälä frequency squared, $N^{2}$, which is defined as $\frac{g}{T}\left[\frac{\partial T}{\partial z}+\frac{g}{c_{\mathrm{p}}}\right]$, where $T$ is the virtual temperature observed with RASS, $g$ is the gravitational acceleration, and $c_{\mathrm{p}}$ is the specific heat capacity of dry air at a constant pressure. The $N^{2}$ results with 10-min resolution in Fig. 17 indicate a layer of higher $N^{2}$ at $4-5 \mathrm{~km}$ altitude throughout the campaign period. Referring to the radiosonde profiles, this stable layer appeared near the freezing level.

We aimed to compare details of the enhancements of $N^{2}$ at 2-6 km altitude between the RASS and simultaneous radiosonde profiles. Balloon release timings are indicated in Fig. 17 (top panel). We selected six cases when
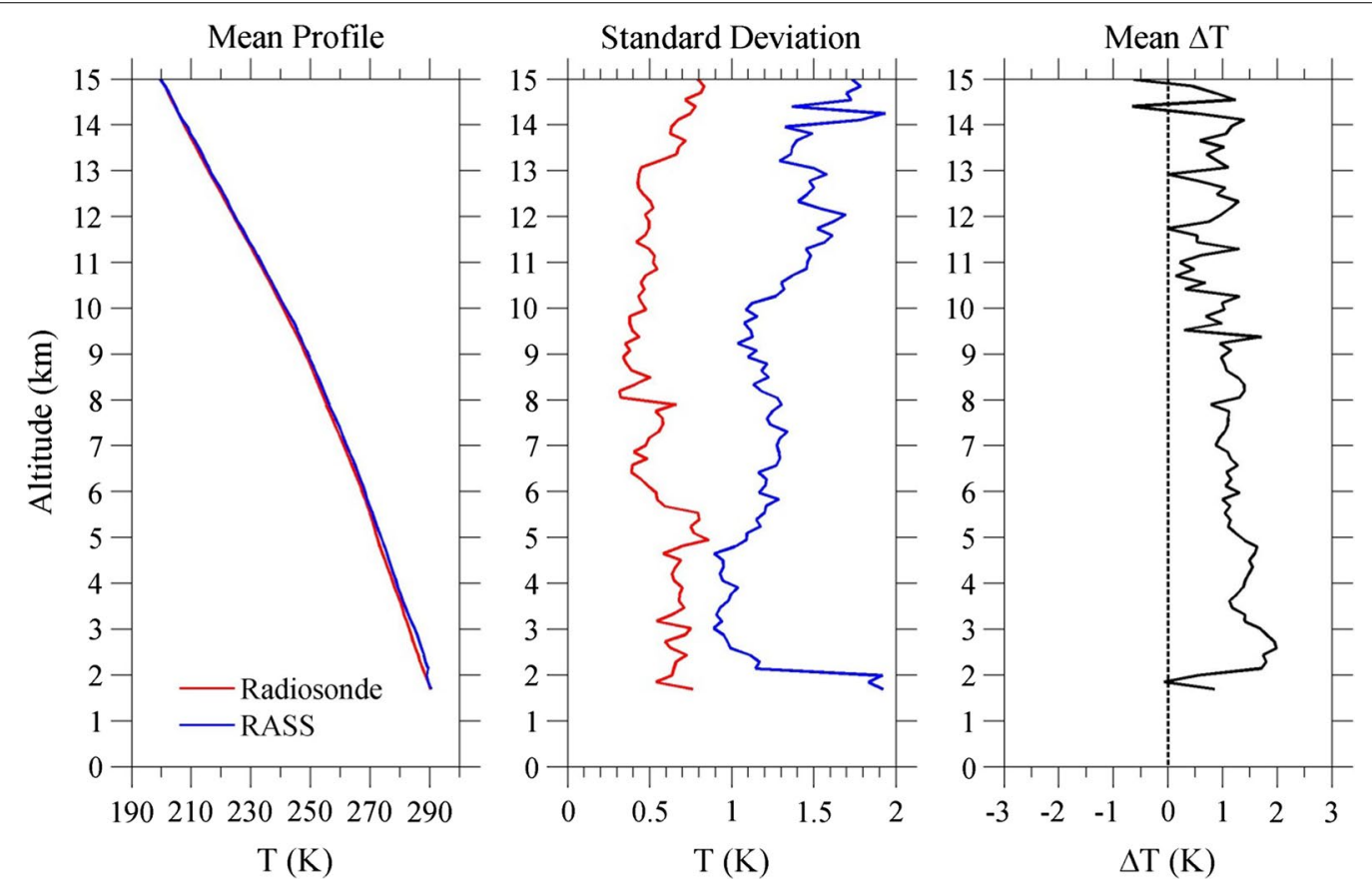

Fig. 15 Comparison of the EAR-RASS temperature profile averaged over all 10-min resolution results (blue) and the mean of 12 radiosonde results (red) from August 29 to September 3, 2016. Standard deviation of the temperature for RASS and radiosondes during the campaign is plotted in the middle panel. The mean temperature difference is shown in the right panel 


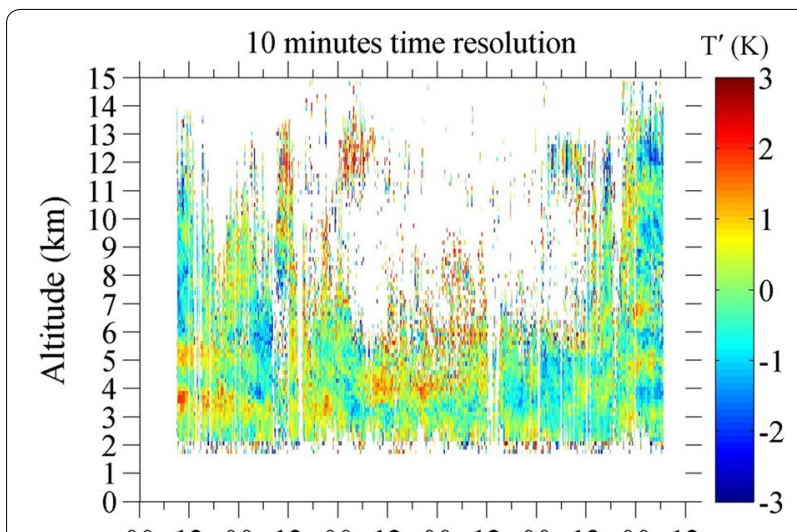

$\begin{array}{llllllllllll}00 & 12 & 00 & 12 & 00 & 12 & 00 & 12 & 00 & 12 & 00 & 12\end{array}$

29-Aug 30-Aug 31-Aug 01-Sep 02-Sep 03-Sep

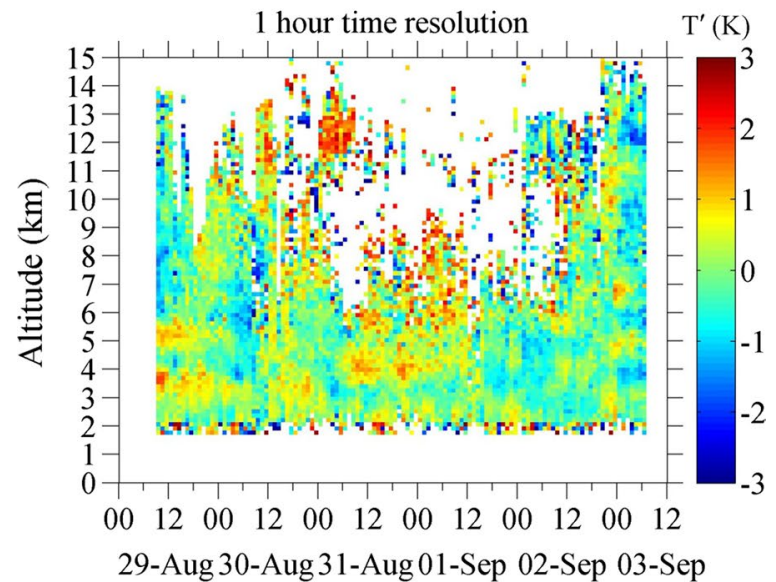

Fig. 16 Time and height variations of the temperature perturbations during the EAR-RASS campaign from August 29 to September 3,

2016, where the averaging was conducted for $10 \mathrm{~min}$ (top panel) and $1 \mathrm{~h}$ (bottom panel), respectively

the RASS data were available for one hour after the balloon launch as shown in Fig. 18. These radiosondes are also indicated in Table 5. For the three launches on September 2, RASS data were also available. But, the layered structure of $N^{2}$ was not evident, so, we eliminated these cases from the comparison. Between 2 and $6 \mathrm{~km}$ altitude, the RASS and radiosonde results in Fig. 18 show a reasonable agreement of the overall height structure, although considerable fluctuations were recognized.

During 09:00-12:00 LT on August 30, the temperature suddenly became colder by about $1-2 \mathrm{~K}$, extending from $4 \mathrm{~km}$ to about $10 \mathrm{~km}$. The colder $T$ started at 09:00 LT and continued until noon. However, there is no clear feature in the zonal wind in Fig. 19. Precipitation was not recognized during this cold event.

On September 1, the temperature profiles showed enhanced fluctuations. Figure 19 shows the time and
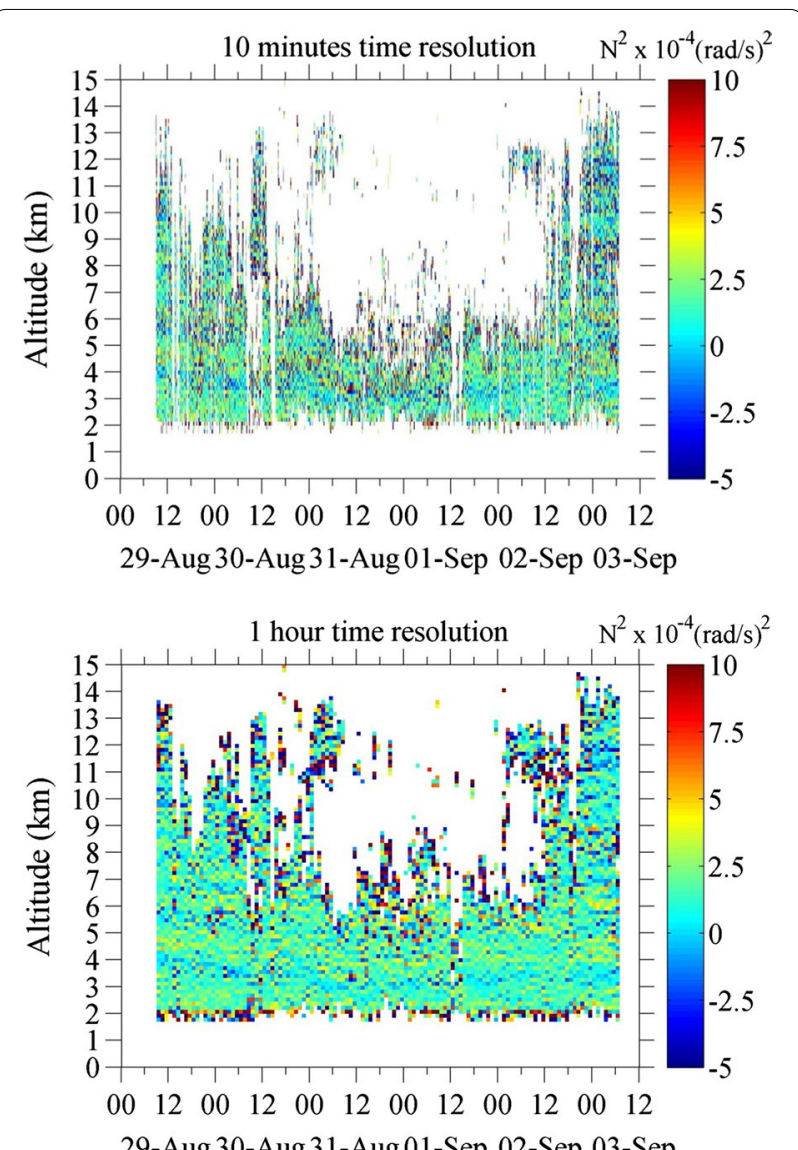

Fig. 17 Time and height variations of $N^{2}$ using the $T$ values in Fig. 14 for the averaging of $10 \mathrm{~min}$ (top panel) and $1 \mathrm{~h}$ (bottom panel), respectively. Arrows in the top panel indicate radiosonde launch timing, where only profiles indicated in black are used for comparison of $N^{2}$ with RASS in Fig. 18

height variations of the zonal (eastward) and meridional (northward) wind velocity observed with the standard five-beam mode of EAR. A peculiar wind perturbation was recognized on September 1. Figure 20 shows the enlarged plots of wind velocity and temperature on September 1 with the 10-min time resolution, which vividly exhibited large and rapid variations in both the zonal and meridional wind velocity at $2-12 \mathrm{~km}$ altitude in the afternoon. The structure of the zonal and meridional winds was generally systematic. The vertical wind velocity indicated a strong downdraft wind below about $10 \mathrm{~km}$, which changed direction to upward above about $10 \mathrm{~km}$. Figure 21 shows the radar reflectivity results of the micro rain radar (MRR) operating at the EAR site, indicating rain clouds at 12:00-15:00 LT, with a maximum intensity at 12:30 LT.

Infrared satellite images with the Himawari-8 in Fig. 22 indicate that from 09:00 LT until 21:00 LT on September 


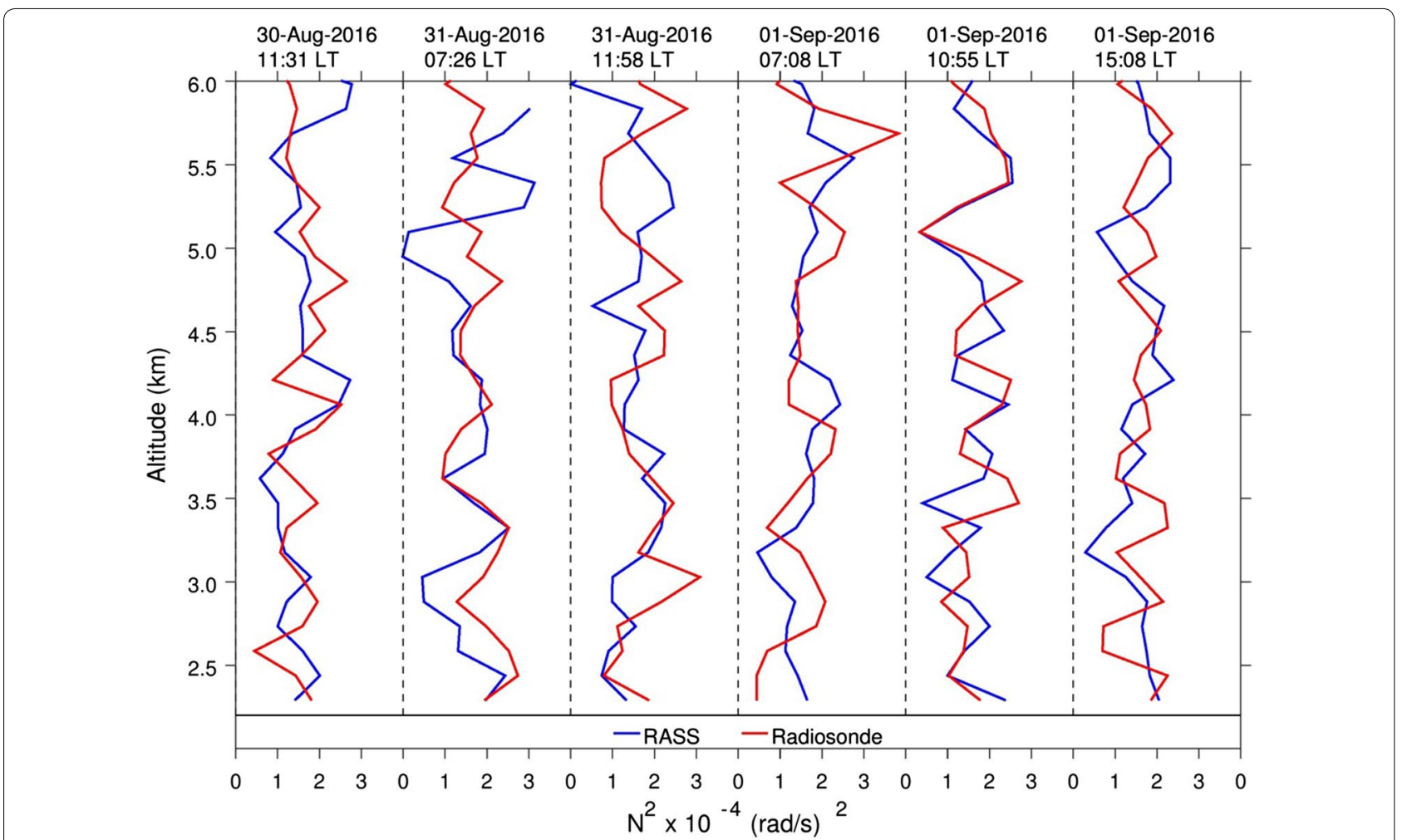

Fig. 18 Comparison of individual $N^{2}$ profiles between RASS and radiosondes. The $N^{2}$ with RASS is derived from the mean temperature profile averaged for one hour after the radiosonde launch
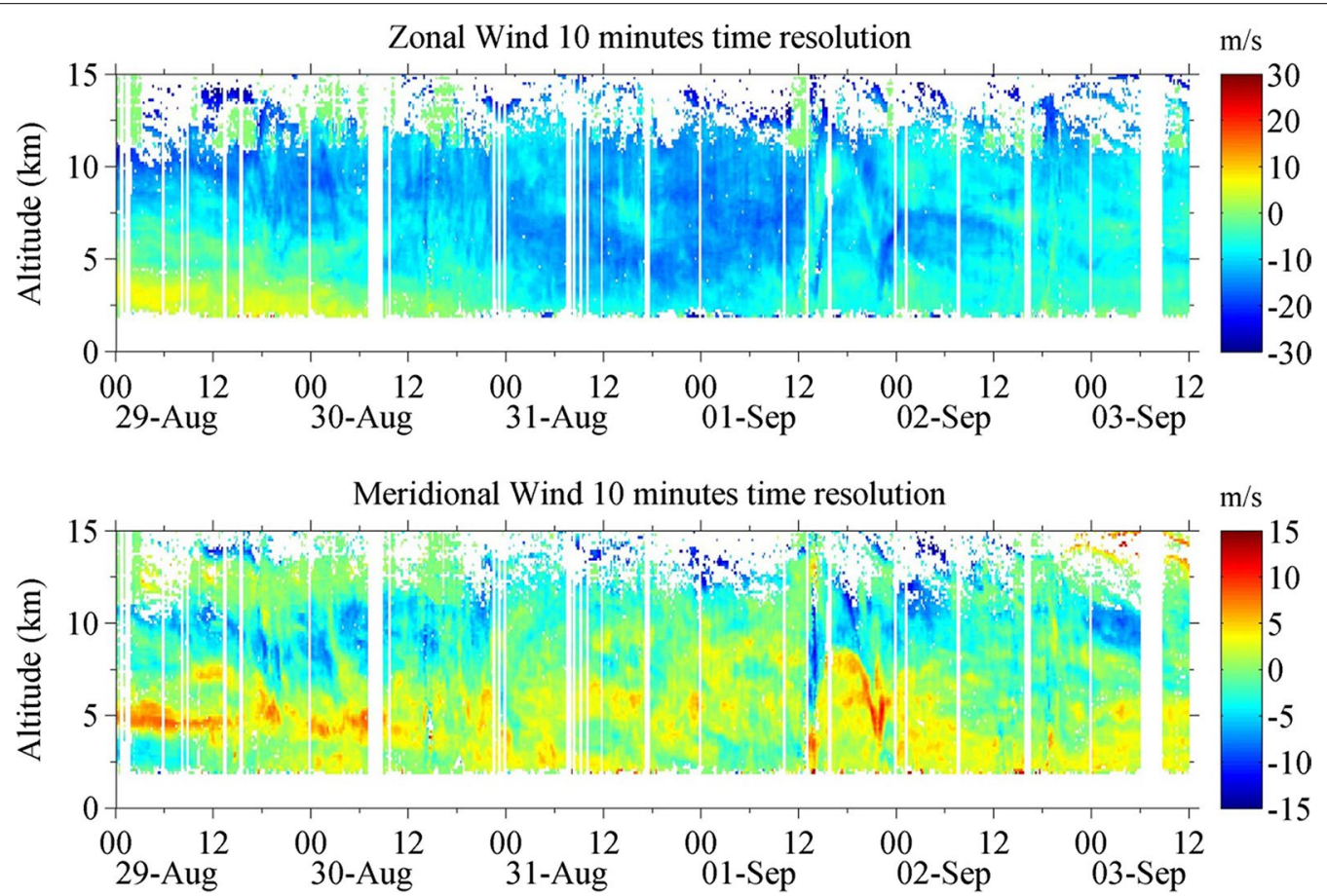

Fig. 19 Time and height variations of the eastward (top) and northward (bottom) wind velocity observed with the standard five-beam method with EAR from August 29 to September 3, 2016 

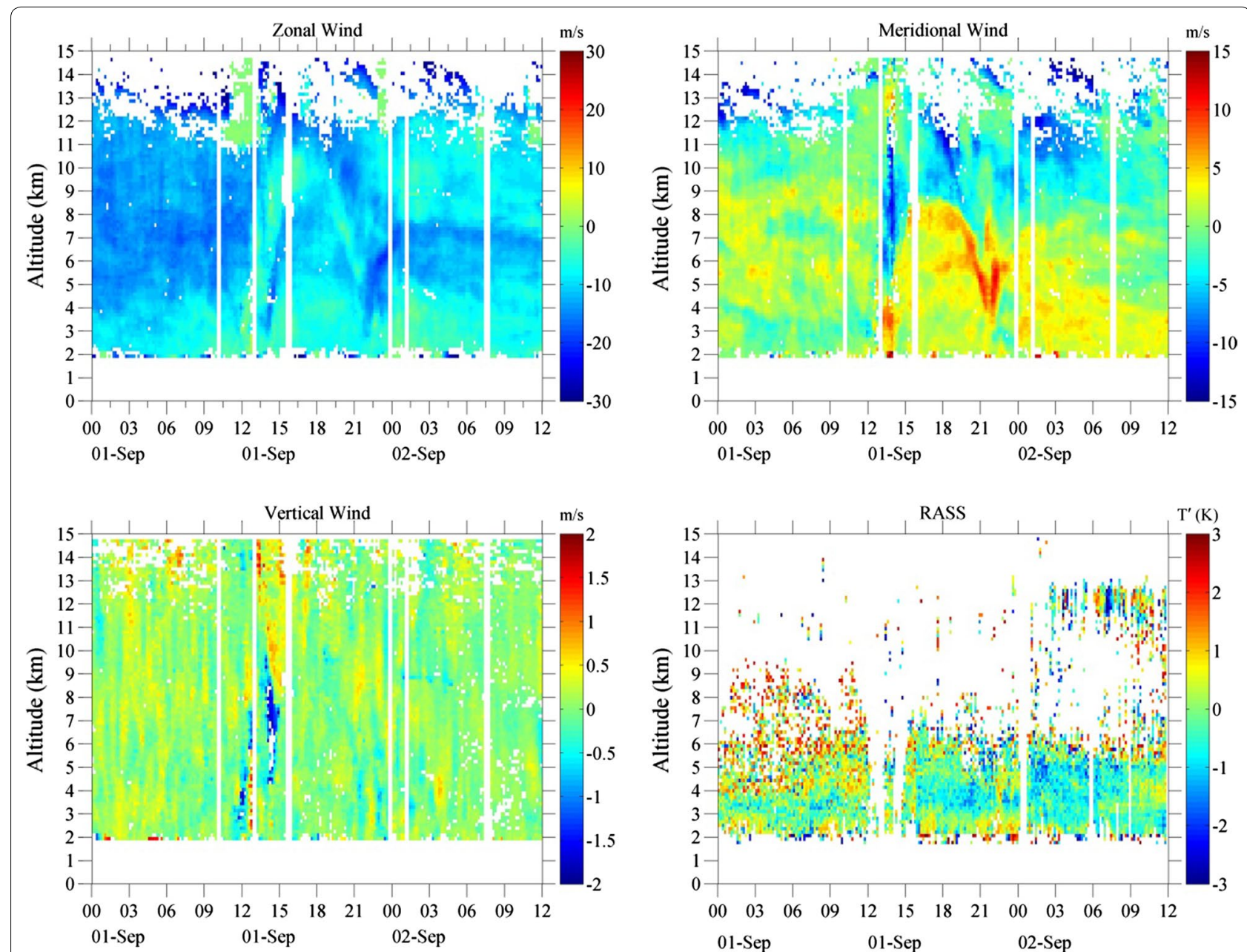

Fig. 20 Enlarged plots of $u$ (top-left), $v$ (top-right), $w$ (bottom-left), and $T^{\prime}$ (bottom-right) from 00:00 LT on September 1 to 12:00 LT on September 2, 2016. Averaging time is $10 \mathrm{~min}$

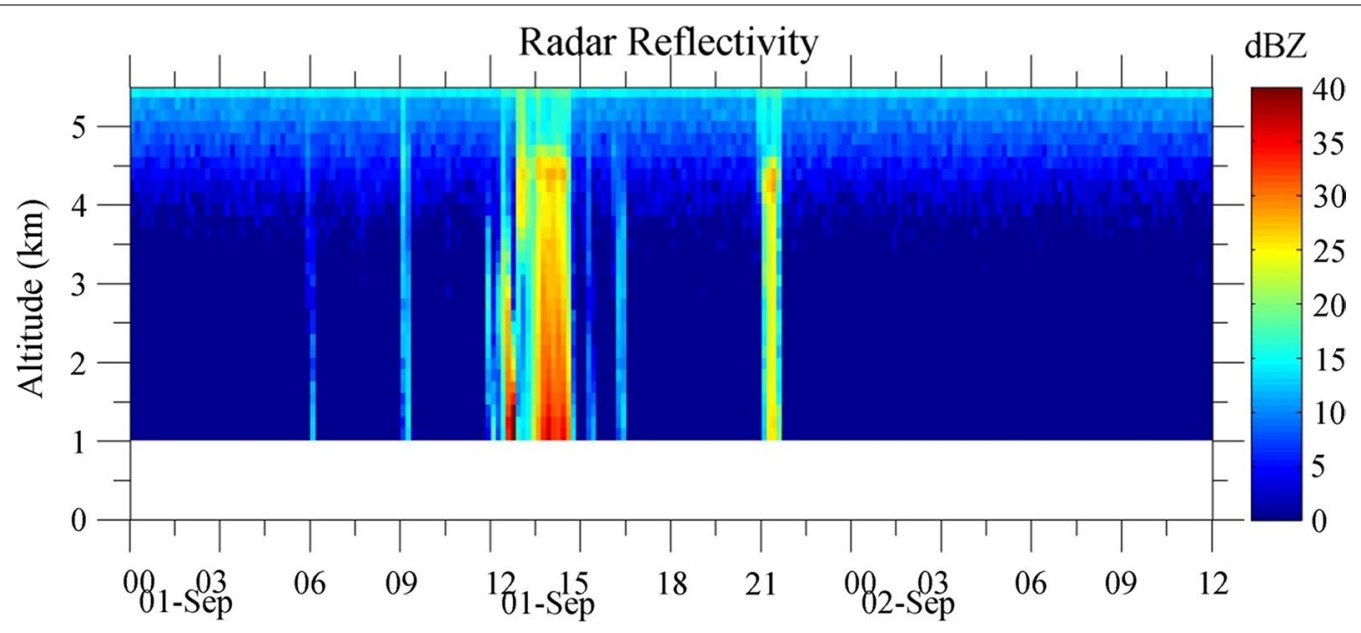

Fig. 21 Radar reflectivity observed with MRR at the EAR site from 00:00 LT on September 1 to 12:00 LT on September 2, 2016. Averaging time is $10 \mathrm{~min}$ 

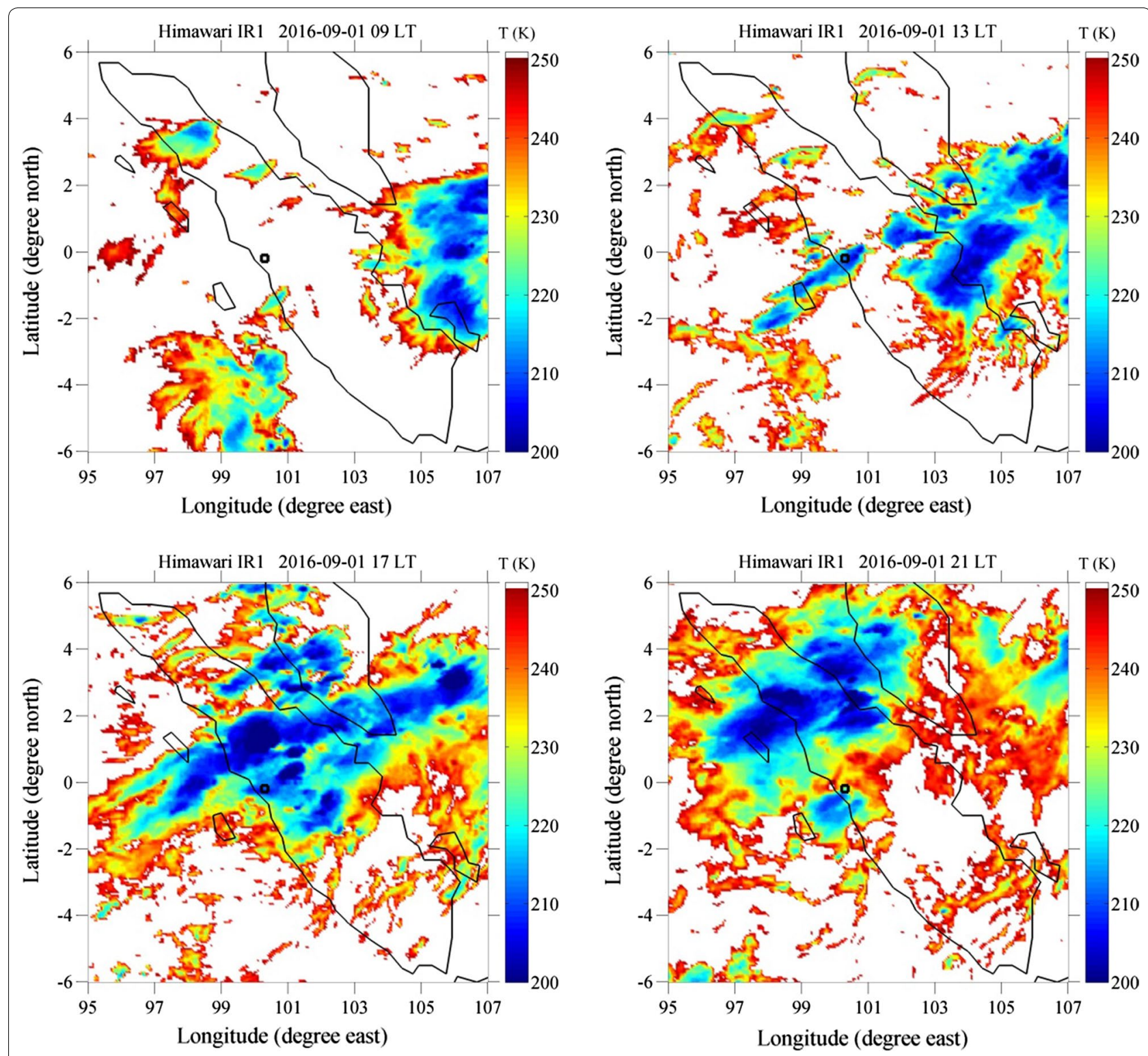

Fig. 22 Himawari satellite images at 09, 13, 17, and 21 LT on September 1, 2016. Black circle indicates the location of EAR

1 developed clouds passed over the EAR site from east to west, which seemed to produce the wind velocity disturbances. Using the radiosonde data, we derived the convective available potential energy (CAPE) as an index of atmospheric convective activity. The CAPE at 10:55 LT on September 1 was as high as $4.4 \mathrm{~J} \mathrm{~kg}^{-1}$. Temperature perturbations were enhanced in the morning of September 1 as seen in Fig. 16. However, the peculiar wind disturbances occurring during 12:00-23:00 LT, shown in Fig. 20, did not coincide with a signal of temperature variations.

\section{Concluding remarks}

In this study, we carried out a total of eight campaigns of EAR-RASS in 2016, aiming to establish a stable temperature observation system with RASS. First, we examined the Bragg condition of RASS echoes, separating it into orthogonal and resonance conditions.

Regarding the orthogonal condition, we adopted the 3-D ray tracing of acoustic waves for determining the appropriate antenna directions for obtaining RASS echoes. The 3-D ray tracing worked well when referring to the actual wind velocity profiles observed with EAR. We 
selected the appropriate antenna beam directions every few hours during the campaign. Then, we obtained the temperature profiles continuously. The range resolution was $150 \mathrm{~m}$. One cycle of RASS and turbulence echo measurements lasted $2 \mathrm{~min}$ using the standard mode only, while it lasted 3 min when the additional radial wind measurements were added.

Second, we investigated the acoustic sources, including the location of speakers and the sweep frequency range of the FM-chirped acoustic signals. We found that the speakers located in the center of the EAR antenna were most effective, but speakers outside the antenna were also useful for obtaining the RASS echoes in the lower altitudes when the wind velocity became large.

We applied a spectral fitting for RASS echoes assuming a Gaussian distribution. We studied the effects of the background winds on the estimation of the true sound speed from the apparent sound speed, which contains the projection of the background winds onto the radial direction. We found that the accuracy of the RASS temperature improved by using direct measurements of the radial winds in the same directions as the RASS beams.

After screening unrealistic values, referring to the mean temperature profile obtained by radiosondes, we obtained the temperature profiles for the five beam directions. Then, all the available RASS results were projected on the single height coordinate that is used for the standard five-beam mode, where the interpolation was done along height within a height interval of up to $600 \mathrm{~m}$. Finally, we constructed the RASS temperature data, averaging over the five beams, with time resolutions of 3, $10 \mathrm{~min}$, and $1 \mathrm{~h}$. The RASS temperature with 10 -min resolution was determined at $2-6 \mathrm{~km}$ with $50-80 \%$ availability, and up to about $14 \mathrm{~km}$ with about $10 \%$ availability. Thus, we have constructed temperature datasets, which will be available for the scientific community via the IUGONET system (www.iugonet.org).

We launched radiosondes between August 30 and September 2, 2016 and compared the temperature profiles with the RASS results, showing a good consistency between the profiles. However, we noticed a shift in these profiles along altitude probably due to a possible discrepancy in the height coordinate for EAR. The standard deviation from the mean temperature difference was about $0.4 \mathrm{~K}$. In a few cases, RASS measured the temperature up to the tropopause, although the correction of the background winds was not sufficient above about $11 \mathrm{~km}$.

We found a few interesting meteorological disturbances that occurred between August 30 and September 1, 2016. A preliminary report was presented on the behavior of the wind velocity and temperature variations in association with the rain data and satellite images on September 1. Details of the disturbances will be further investigated in a future study. Preliminary analysis of these two events showed that EAR-RASS can provide the temperature profiles together with the three components of wind velocity, which are useful for the studies of peculiar atmospheric phenomena in the equatorial regions.

The EAR observatory, having many remote sensing and in situ instruments, plays an important role in the investigation of the convective activities associated with cloud clusters. The EAR observatory is a core of a growing regional network in the Southeast Asia, which will improve our knowledge of various equatorial phenomena.

\section{Abbreviations \\ EAR: equatorial atmosphere radar; RASS: radio acoustic sounding system; WPR: wind profiling radar; MST: mesosphere-stratosphere-troposphere; MRR: micro rain radar; CAPE: convective available potential energy; IUGONET: Inter-univer- sity Upper atmosphere Global Observation NETwork.}

\section{Authors' contributions}

IJ conducted the EAR-RASS experiments, including radiosonde launches and MRR, and joined data interpretation. HT designed the acoustic transmitting system and developed the 3-D ray-tracing method. N carried out analysis of the EAR-RASS data and participated in the discussions. $\mathrm{HH}$ led the data analysis of EAR wind and RASS temperature data. H led the EAR-RASS experiment. TT coordinated the EAR-RASS experiments and led the overall data analysis. All authors read and approved the final manuscript.

\section{Authors' information}

The author (HT) is now at ENEGATE, Co. Ltd., Osaka, Japan. The author (TT) works at Research Organization of Information and Systems (ROIS), Tokyo, Japan. The author $(\mathrm{N})$ is a researcher from the Center for Atmospheric Science and Technology, National Institute of Aeronautics and Space (LAPAN), Indonesia, studying at Kyoto University, Japan.

\section{Author details}

${ }^{1}$ Center for Atmospheric Science and Technology, National Institute of Aeronautics and Space (LAPAN), Bandung, Indonesia. ${ }^{2}$ Research Institute for Sustainable Humanosphere (RISH), Kyoto University, Kyoto, Japan.

\section{Acknowledgements}

The EAR observatory is operated jointly between the Research Institute for Sustainable Humanosphere (RISH), Kyoto University, Japan and the Indonesian National Institute of Aeronautics and Space (LAPAN). This study is supported by the Asia Research Node (ARN) of RISH, Kyoto University. The authors would like to thank Syafrijon and his colleagues at the EAR site who have helped to make the EAR-RASS campaign a success. We also appreciate the devoted support by Yuki Shiono, Soni Aulia Rahayu, Ginaldi Ari Nugroho, and Siti Azizah. This study is partly supported by JSPS KAKENHI Grant Numbers JP15H03724, JP17H00852, and 22253006. One of the authors (N) received a scholarship for his Ph.D. from the Program of Research and Innovation in Science and Technology (RISET-Pro), Ministry of Research, Technology, and Higher Education (RISTEKDIKTI) of Indonesia.

\section{Competing interests}

The authors declare that they have no competing interests.

\section{Availability of data}

The EAR-RASS virtual temperature and EAR wind data were provided by RISH and LAPAN. Radiosonde data were provided by LAPAN. The Himawari-8 satellite images are released by the Japan Meteorological Agency with 10-min time resolution. The hourly Himawari-8 IR1 data also can be found at http:// weather.is.kochi-u.ac.jp/archive-e.html. 
Funding

This study is partially supported by JSPS KAKENHI Grant Numbers JP15H03724, JP17H00852, 22253006, and LAPAN.

\section{Appendix: Relation between the sound speed and the atmospheric temperature}

WPR detects radio wave scattering due to small variations in the refractive index, $n$, which is a function of the atmospheric density, humidity, and temperature. Changes in the atmospheric density accompanying the sound waves produce periodic perturbations of $n$, which can be a target for WPR. We estimate the sound speed from the Doppler shift of the RASS echo. Then, the atmospheric temperature can be determined from the relation that the speed of sound, $C_{\mathrm{s}}\left(\mathrm{m} \mathrm{s}^{-1}\right)$, is proportional to the square root of the atmospheric temperature, $T(\mathrm{~K}) . C_{\mathrm{s}}$ is determined by the characteristics of the propagation medium, such as its pressure, density, and temperature. Under the standard atmospheric condition, $C_{\mathrm{s}}$ on the ground is about $340 \mathrm{~m} \mathrm{~s}^{-1}$, and, as the altitude goes higher, $C_{\mathrm{s}}$ decreases. We briefly introduce the relation between $C_{\mathrm{s}}$ and $T$ below.

Assuming an adiabatic condition, we adopt the equation of state of ideal gas and the wave equation of sound. Then, $C_{\mathrm{s}}$ can be expressed in the following equation:

$$
C_{\mathrm{s}}=\sqrt{\gamma \frac{R}{M} T}=K \sqrt{T},
$$

where $\gamma$ is the specific heat ratio, $R$ is the gas constant, and $M$ is the mean molecular weight. Note that $K$ is a constant, determined by $M$, and $\mathrm{K}$ is about $20.047\left(=\mathrm{K}_{\mathrm{d}}\right)$ in a dry atmosphere. However, in a moist atmosphere below about $10 \mathrm{~km}$ in the tropics, $\mathrm{K}$ varies depending on the humidity. It is difficult, however, to continuously monitor the humidity during RASS experiments, so we substitute $K_{\mathrm{d}}$ for the dry atmosphere in estimating the temperature, resulting in the determination of the virtual temperature, $T_{\mathrm{v}}$, which is slightly higher than $T$ by a few degrees in the lower troposphere below about $8 \mathrm{~km}$ in the tropics. $T_{\mathrm{v}}$ is approximately related to $T$ as follows:

$$
T_{\mathrm{v}} \approx\left(1+0.61 \frac{m_{\mathrm{e}}}{m_{\mathrm{d}}}\right),
$$

where $m_{\mathrm{e}}$ and $m_{\mathrm{d}}$ are the weights of the water vapor and the dry atmosphere, respectively, and this ratio is called the water vapor mixing ratio. $T_{\mathrm{v}}$ is commonly used in meteorology, which is sometimes useful in investigations of the atmospheric condition, including both sensible and latent heat energy.

\section{Publisher's Note}

Springer Nature remains neutral with regard to jurisdictional claims in pub-

lished maps and institutional affiliations.
Received: 4 September 2017 Accepted: 17 January 2018

Published online: 07 February 2018

\section{References}

Adachi T (1996) Detailed temperature structure of meteorological disturbances observed with RASS (radio acoustic sounding system). Ph.D Dissertation, Kyoto University

Adachi T, Tsuda T, Masuda Y, Takami T, Kato S, Fukao S (1993) Effects of a ratio between acoustic and radar pulse lengths on accuracy of RASS temperature measurements. Radio Sci 28:571-583

Alexander SP, Tsuda T, Furumoto J, Shimomai T, Kozu T, Kawashima M (2006) A statistical overview of tropospheric convection during CPEA campaign. J Meteorol Soc Jpn 84A:57-93

Behrendt (2005) A temperature measurements with lidar. In: C. Weitkamp (ed) Lidar: range-resolved optical remote sensing of the atmosphere. Springer series in optical sciences, vol 102. Springer-Verlag, New York, pp 273-305

Clifford C, Wang T (1977) The range limitation on radar-acoustic sounding system (RASS) due to atmospheric refractive turbulence. IEEE Trans Antenna Propag. https://doi.org/10.1109/tap.1977.1141574

Emanuel KA (1987) An air-sea interaction-model of intraseasonal oscillations in the tropics. J Atmos Sci 44:2324-2340

Frank WM, Cohen C (1987) Simulation of tropical convective systems, Part I: A cumulus parameterization. J Atmos Sci 44:3787-3799

Fukao S (2006) Coupling processes in the equatorial atmosphere (CPEA): a project overview. J Meteorol Soc Jpn 84A:1-18

Fukao S, Hashiguchi H, Yamamoto M, Tsuda T, Nakamura T, Yamamoto MK, Sato T, Hagio M, Yabugaki Y (2003) Equatorial atmosphere radar (EAR): system and description and first results. Radio Sci 38(3):1053. https://doi. org/10.1029/2002rs002767

Furumoto J, Tsuda T, Iwai S, Kozu T (2006) Continuous humidity monitoring in a tropical region with the equatorial atmosphere radar (EAR). J Atmos Ocean Technol 23:538-551

Marshall JM, Peterson AM, Barnes AA Jr (1972) Combined radar-acoustic sounding system. Appl Opt 11:108-112

Masuda Y (1988) Influence of wind and temperature on the height limit of a radio acoustic sounding system. Radio Sci 23:647-654

Masuda Y, Awaka J, Okamoto K, Tsuda T, Fukao S, Kato S (1990) Echo power loss with RASS (radio acoustic sounding system) due to defocusing effects by distorted acoustic wave front. Radio Sci 25:975-982

Masuda Y, Awaka J, Nakamura K, Adachi T, Tsuda T (1992) Analysis of the radio acoustic sounding system using a chirped acoustic wave. Radio Sci 27:681-691

Matuura N, Masuda Y, Inuki H, Kato S, Fukao S, Sato T, Tsuda T (1986) Radio acoustic measurement of temperature profile in the troposphere and lower stratosphere. Nature 323:426-428

May PT, Strauch RG, Moran KP (1988) The altitude coverage of temperature measurements using RASS with wind profiler radars. Geophys Res Lett 15(12):1381-1384. https://doi.org/10.1029/gl015i012p01381

May PT, Adachi T, Tsuda T, Lataitis RJ (1996) The spatial structure of RASS echoes. J Atmos Ocean Technol 13:1275-1290

Peters G (2000) History of RASS and its use for turbulence measurements. In: IGARSS 2000, Proceedings of the geoscience and remote sensing symposium, 2000. IEEE

Ratnam MV, Alexander SP, Kozu T, Tsuda T (2009) Characteristics of gravity waves observed with intensive radiosonde campaign during NovemberDecember 2005 over Western Sumatera. Earth Planets Space 61(8):983993. https://doi.org/10.1186/bf03352948

Sarma TVC, Rao DN, Furumoto J, Tsuda T (2008) Development of radio acoustic sounding system (RASS) with Gadanki MST radar-first results. Ann Geophys 26(9):2531-2542

Sarma TVC, Kodama Y, Tsuda T (2010) Characteristics of atmospheric waves in the upper troposphere observed with the Gadanki MST Radar-RASS. J Atmos Solar Terr Phys 73(2011):1020-1030. https://doi.org/10.1016/j. jastp.2010.08.010

Spano E, Ghebrebrhan O (1996) Pulse coding techniques for ST/MST radar systems: a general approach based on a matrix formulation. IEEE Trans Geosci Remote Sens 34:304-316 
Tsuda T, Masuda Y, Inuki H, Takahashi K, Takami T, Sato T, Fukao S, Kato S (1989) High time resolution monitoring of tropospheric temperature with a radio acoustic sounding system (RASS). Pure appl Geophys 130:497-507 Tsuda T, Adachi T, Masuda Y, Fukao S, Kato S (1994) Observations of tropospheric temperature fluctuations with the MU radar/RASS. J Atmos Ocean Technol 11:50-62

Welsh PT, Santos P, Christopher CG (1999) A study of sea breeze convective interactions using mesoscale numerical modeling. Natl Weather Dig Montgomery AL 23(3):33-45
Westwater ER (1970) ground-based determination of temperature profiles by microwaves. Ph.D. Dissertation, University of Colorado

Wilks DS (2006) Statistical methods in the atmospheric sciences, 2nd edn. Academic Press, New York

Zhang D-L, Fritsch JM (1988) Numerical sensitivity experiments on structure, evolution and dynamics of two mesoscale convective systems. J Atmos Sci 45:261-293

\section{Submit your manuscript to a SpringerOpen ${ }^{\circ}$ journal and benefit from:}

- Convenient online submission

- Rigorous peer review

- Open access: articles freely available online

- High visibility within the field

- Retaining the copyright to your article

Submit your next manuscript at $\boldsymbol{\nabla}$ springeropen.com 